\title{
Ammonia plasma-treated carbon nanotube/epoxy composites and their use in sensing applications
}

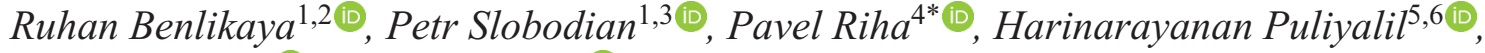 \\ Uros Cvelbar ${ }^{5,6}$, Robert Olejnik $^{1 \odot}$ \\ ${ }^{1}$ Centre of Polymer Systems, University Institute, Tomas Bata University, Trida T. Bati 5678, 76001 Zlin, Czech Republic \\ ${ }^{2}$ Department of Secondary Science and Mathematics Education, Faculty of Necatibey Education, Balikesir University, \\ 10100, Balikesir, Turkey \\ ${ }^{3}$ Tomas Bata University, Faculty of Technology, Polymer Centre, T.G.M. 275, 76001 Zlin, Czech Republic \\ ${ }^{4}$ The Czech Academy of Sciences, Institute of Hydrodynamics, Pod Patankou 5, 16612 Prague 6, Czech Republic \\ ${ }^{5}$ Jožef Stefan Institue, Jamova cesta 39, SI-1000 Ljubljana, Slovenia \\ ${ }^{6}$ Jožef Stefan International Postgraduate School, Jamova cesta 39, SI-1000 Ljubljana, Slovenia
}

Received 15 June 2021; accepted in revised form 1 September 2021

\begin{abstract}
Epoxy composites filled by multiwalled carbon nanotubes treated by inductively coupled ammonia plasma were prepared to improve composite intrinsic properties. The ammonia plasma treatment generated amine and oxygenated groups on the carbon nanotube surface, which facilitated its interaction with the epoxy ring and restricted the slippage of epoxy from the carbon nanotube surface. As a result, an improvement in the elastic modulus of the composite by the embedded carbon nanotubes and a decrease in the glass transition temperature and the cure degree were found. It indicated a strengthening effect of the carbon nanotube filler in the epoxy matrix explained by the generation of chemical reaction pathways between treated filler and the epoxy matrix detected by Fourier transform infrared spectroscopy and X-ray photoelectron spectroscopy during different stages of the composite formation. To demonstrate the use of carbon nanotube-filled epoxy composites, a microstrip resonant vapor sensor was assembled that was used to detect the occurrence of volatile organic compounds and to monitor the ambient temperature below and over the glass transition temperature.
\end{abstract}

Keywords: polymer composites, carbon nanotubes, plasma treatment, glass transition, microstrip resonant sensor

\section{Introduction}

Carbon nanotubes (CNTs) have been used widely as a filler in polymer composites for their unique electrical, mechanical and structural properties. To overcome the poor dispersion of CNTs in polymer resin and their weak interfacial bonding with polymer matrix, surface treatment of CNTs is required. Carboxyl and amine-functionalized multiwalled carbon nanotubes (MWCNTs) are the examples obtained by commonly used wet chemical or plasma treatment methods [1-3].
Plasma treatment is a solvent-free dry process as compared with chemical one. In addition, chemical functionalization can disrupt the $\pi-\pi$ conjugated structure of CNTs, which can adversely affect their intrinsic thermal conductivities due to phonon scattering from defects [4]. Thus, this treatment has had major attention in the last decade due to maintaining the intrinsic properties of CNTs [5].

CNT-epoxy composites are increasingly employed in several industrial fields, such as automotive, aerospace, energy, and electronics, depending upon the

\footnotetext{
${ }^{*}$ Corresponding author, e-mail: riha@ih.cas.cz (C) BME-PT
} 
enhanced material properties by the nanofillers [6]. Therefore, it is important to prepare and examine the properties of epoxy composites with CNTs functionalized under different conditions. There have been many studies comparing thermal [7-9], mechanical [10-12] and thermomechanical properties [13] of the epoxy composites involving amine and/or carboxyl functionalized MWCNTs by chemical treatments. Studies with plasma-treated MWCNTs are less common than those based on the previous approach.

The plasma treatment of MWCNTs used at the preparation of the epoxy composites have been carried out under various conditions, including $\mathrm{Ar} / \mathrm{O}_{2}$ and $\mathrm{Ar} / \mathrm{O}_{2} / \mathrm{N}_{2}$ atmospheres at different plasma powers [14], the presence of oxygen and ammonia atmosphere [15], the combination of continuous and pulsed plasma modes in a nitrogen and hydrogen gas mixture [16], the mixed gas source of helium-oxygen [17-19] at different plasma powers [19], oxygen plasma [20] and inductively coupled plasma (ICPCNT) treatment with mechanical shear force (MSFCNT) under nitrogen [21]. It has been seen that ammonia plasma treatment is limited in those studies. Thermal [14-16, 21], mechanical [14-21], electrical [17], and wetting [19] properties of the epoxy composites with the plasma-treated CNT samples have been examined. However, the information on cure degree C.D. of these composites is not provided in these studies, which could help understand the change in thermal and mechanical properties of epoxy composites with plasma-treated MWCNTs compared to those of pure epoxy or the epoxy composites with chemically treated MWCNTs. For this reason that the cure degree is not stated in many epoxy studies, the effect of even unmodified CNTs on the glass transition temperature $T_{\mathrm{g}}$ of epoxy composites remains unclear [22]. As a result of the interaction of CNTs modified by plasma and chemical methods with epoxy, the cure degree in the composites will be different due to the diversity of their surface properties. To know/compare the relations among cure degree, thermal and mechanical properties, and the effect of the treatment methods for MWCNTs on the relations can provide the opportunity to prepare epoxy composites as required. Thus, it is important to carry out studies that will also help to uncover the deficiencies in the epoxy composites with plasmatreated MWCNTs.

In the present work, epoxy composites with pristine and ammonia plasma-treated MWCNTs at two different $\mathrm{NH}_{3}$ plasma conditions were prepared. The effect of the treatment method and loading of MWCNTs on the cure degree, the glass transition temperature $T_{\mathrm{g}}$ and the elastic modulus of these epoxy composites were tested by using Fourier transform infrared spectroscopy (FTIR), X-ray photoelectron spectroscopy (XPS), scanning electron microscopy (SEM), differential scanning calorimeter (DSC) and creep measurement. The aim was to explore and determine the relations among glass transition temperature, cure degree, the elastic modulus of epoxy composites when assembled from differently prepared MWCNTs and explore potentials for improving the composite properties through plasma tailoring of fillers. To demonstrate the practical use of prepared epoxy composites, the microstrip resonant sensor was made. The sensor adsorbed the molecules of volatile organic compounds (VOCs) or by thermal volume changes altered the arrangement of embedded MWCNT conductive network and changed its electrical resistance, impedance, and consequently, the reflection coefficient spectrum that was used to identify the occurrence of a particular VOC or temperature both below and above $T_{\mathrm{g}}$.

\section{Experimental}

\subsection{Materials}

Diglycidyl ether of bisphenol A (DGEBA) and hexahydro-4-methylphthalic anhydride (HMPA) were supplied from Sigma Aldrich (St. Louis, MO, USA). The weight ratio of the epoxy to HMPA was 1:5. Triethylamine (TEA) was obtained from Merck (Darmstadt, Germany), which amount was $0.5 \%$ of the weight of DGEBA. MWCNTs (BAYTUBES C70 P) used in this study were purchased from Bayer Material Science A.G. (Leverkusen, Germany).

\subsection{Plasma treatment}

The carbon nanotubes were exposed to ammonia $\left(\mathrm{NH}_{3}\right)$ plasma in the discharge chamber shown in Figure 1 for 10 minutes. The system was pumped down using a two-stage oil Leybold rotary pump with a pumping speed of $16.7 \cdot 10^{-3} \mathrm{~m}^{3} / \mathrm{s}$. The discharge-reactor chamber was a Pyrex cylinder with a length of $270 \mathrm{~mm}$ and an inner diameter of $320 \mathrm{~mm}$. The plasma was created using an inductively coupled radio frequency (RF) generator, operating at a frequency of $27.12 \mathrm{MHz}$ and maximum output power of approximately $1.5 \mathrm{~kW}$. Commercially available ammonia (purity 3.8) was introduced into the discharge 


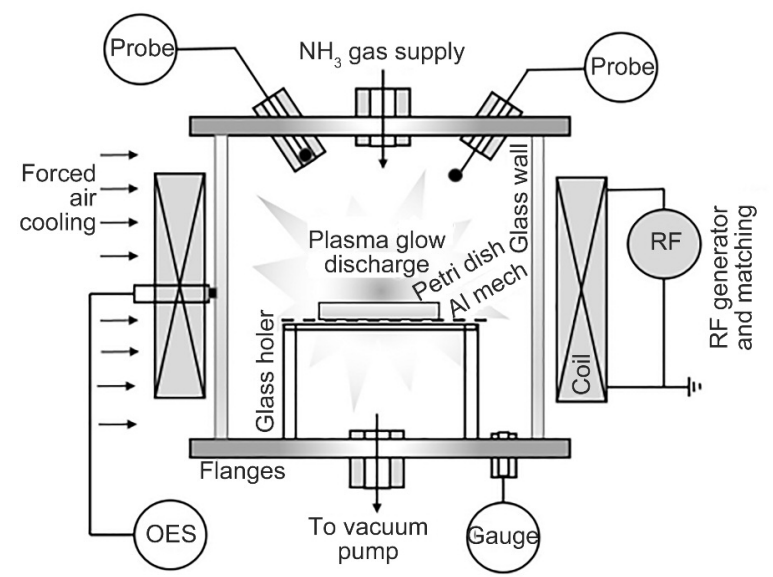

Figure 1. Schematic of plasma experimental system and treatment reactor.

chamber. The pressure was measured by an absolute vacuum gauge and adjusted during continuous pumping by a precise leak valve. In our experiments, the pressure was fixed at two processing pressures: 300 and $40 \mathrm{~Pa}$, and treated MWCNTs were denoted as MWCNT(plasma300) and MWCNT(plasma40), respectively. The MWCNTs were placed into the center of the discharge chamber on a glass petri dish, which was held by aluminum mesh on glass holders.

\subsection{Composite fabrication}

Pristine and treated MWCNTs were dispersed in the curing agent HMPA with ultrasonic treatment for $30 \mathrm{~min}$ at $50^{\circ} \mathrm{C}$. Then epoxy resin and catalyst TEA were added to the system by mechanical mixing with a glass rod. Non-catalyzed epoxy-anhydride systems are very low reactive and, therefore, the reactions between the pairs of epoxy-epoxy or epoxy-curing agents usually take place at a measurable rate only

\subsection{Characterization of MWCNTs and MWCNT-epoxy composites}

The surface treatment of MWCNT samples was studied by high-resolution XPS as well as FTIR spectroscopy. The samples were mounted in the TFA XPS Physical Electronics XPS instrument (Chanhassen, MN, USA). The base pressure in the XPS analysis chamber was about $6 \cdot 10^{-8} \mathrm{~Pa}$. The samples were excited with X-rays over a $400 \mu \mathrm{m}$ spot area with monochromatic $\mathrm{Al} \mathrm{K}_{\alpha 1,2}$ radiation at $1486.6 \mathrm{eV}$. Photoelectrons were detected with a hemispherical analyzer positioned at an angle of $45^{\circ}$ with respect to normal to the sample surface. The energy resolution was about $0.5 \mathrm{eV}$. Survey-scan spectra were made at a pass energy of $187.85 \mathrm{eV}$, while for $\mathrm{C} 1 \mathrm{~s}$ individual high-resolution spectra were taken at a pass energy of $23.5 \mathrm{eV}$ and a $0.1 \mathrm{eV}$ energy step. Since the samples were insulators, an additional electron gun was used to allow for surface neutralization during the measurements.

Fourier-transform infrared analyses of MWCNTepoxy composites were performed on FTIR spectrometer Nicolet IS5 (Thermo Scientific, Waltham, MA, USA) to determine their cure degree using Ge plate for ID5 ATR one. The absorption intensity of the peak between 910 and $920 \mathrm{~cm}^{-1}$ is considered the maximum for uncured epoxy resins, decreasing with the conversion of epoxide groups during the curing cycle, when the conversion of epoxide groups takes place [23]. The intensity of the reference band could be used to understand whether the presence of the MWCNTs has caused any influence in the extension of the conversion of epoxide groups or not. These values of C.D. of epoxy and epoxy composites were determined using Equation (1) used in previous studies [24-26]:

$$
\text { C.D. [\%] }=\frac{A_{\text {benzenring(cured) }} A_{\text {oxirane(uncured) }}-A_{\text {oxirane(cured) }} A_{\text {benzenring(uncured) }}}{A_{\text {benzenring(cured) }} A_{\text {oxirane(uncured) }}} \cdot 100
$$

at temperatures over $200^{\circ} \mathrm{C}$. Basic catalysts such as tertiary amines accelerate the reaction leading to esters and suppress the formation of ether [12]. Thus, TEA was used as a catalyst. The mixtures were poured in a silicon mold of dog-bone specimens and cured for $3 \mathrm{~h}$ at $80^{\circ} \mathrm{C}$ followed by $15 \mathrm{~min}$ at $140^{\circ} \mathrm{C}$ for post-curing. The obtained composites were identified as MWCNT(plasma40)-Epoxy, MWCNT(plasma300)-Epoxy with MWCNT contain 0, 0.2, and 0.4 wt $\%$. where the letter $A$ represents the absorbance values of the peaks.

Furthermore, a transmission accessory was used to examine the effect of the plasma treatments on pristine MWCNTs in powder form prepared by $\mathrm{KBr}$ and the interaction of the MWCNTs with these components by dropping of HMPA and DGEBA on the MWCNT pellets.

The fractured tensile structures of MWCNT-epoxy composites were analyzed by scanning electron 
microscope Vega LMU (Tescan Inc., Warrendale, PA, USA). The samples were deposited on carbon targets and covered with a thin $\mathrm{Au} / \mathrm{Pd}$ layer. Perkin Elmer Pyris 1 was used for DSC measurements of the epoxy composites from 50 to $250^{\circ} \mathrm{C}$ at the rate of $10^{\circ} \mathrm{C} / \mathrm{min}$. Elastic modulus of epoxy composites was determined by a creep test machine when the materials were under the tensile stress with an increasing value from about 0.45 to $11 \mathrm{MPa}$.

\section{Results}

\subsection{MWCNTs}

\subsubsection{XPS measurements}

XPS analysis revealed that the surface of the nontreated sample predominantly contained carbon and a small amount of oxygen. For a better understanding

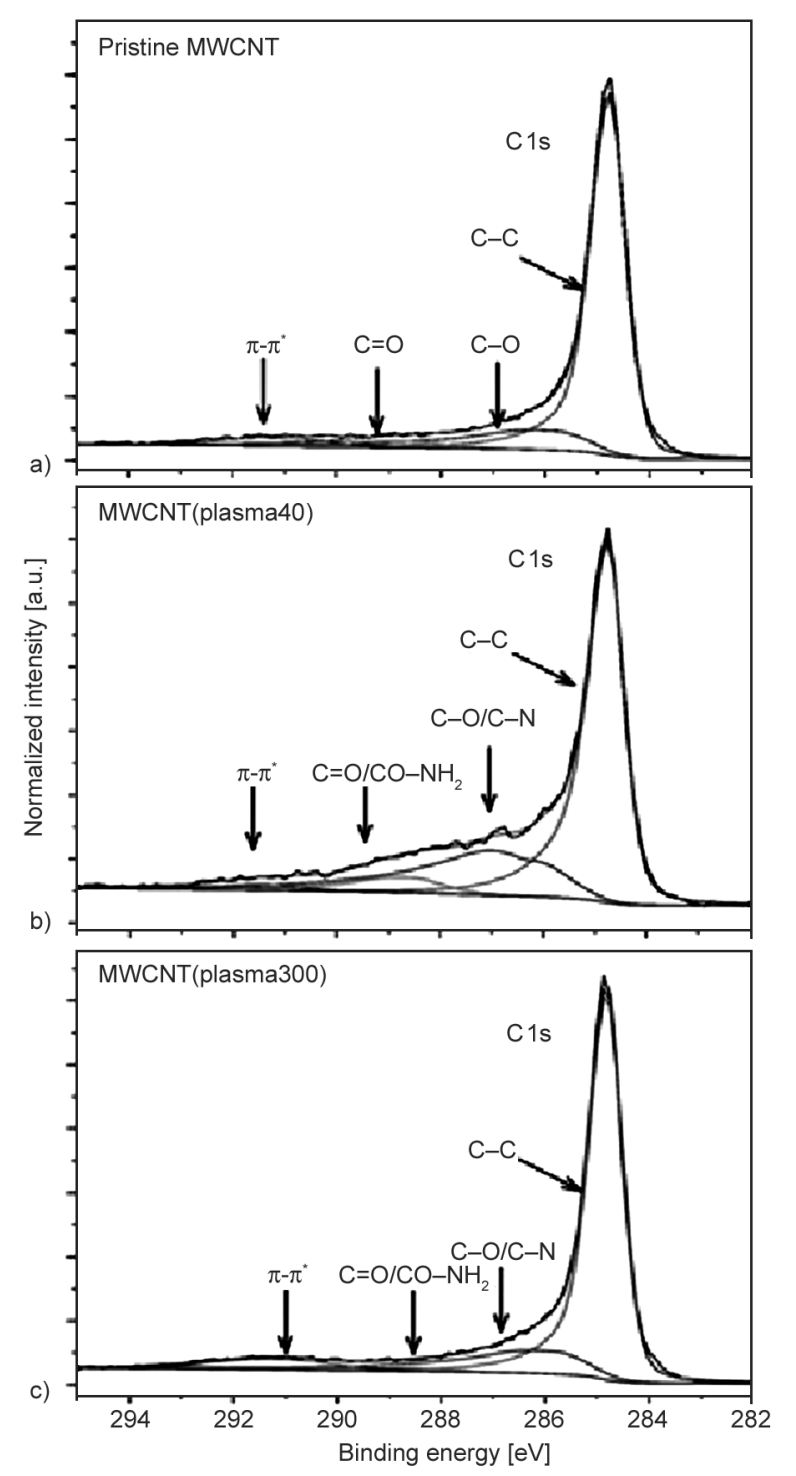

Figure 2. XPS deconvolution of HR C 1s peak for (a) nontreated, (b) plasma40, and plasma300 (3) MWCNT samples. of the chemical modifications of the surface after $\mathrm{NH}_{3}$ plasma treatment, HR C 1s peak is deconvoluted, see Figure 2. The peak at a binding energy of $284.9 \mathrm{eV}$ is assigned to carbon-carbon bonding states. In the case of the pristine sample, the peaks at respective binding energies of $\sim 286$ and $\sim 288 \mathrm{eV}$ are assigned as $\mathrm{C}-\mathrm{O}$ and $\mathrm{C}=\mathrm{O}$ bond types on the surface. The higher energy peak positioned at around $291 \mathrm{eV}$ could be assigned as the $\pi-\pi^{*}$ transition [27]. After the plasma treatment, the peaks at $\sim 286$ and $\sim 288 \mathrm{eV}$ could be overlapped with $\mathrm{C}-\mathrm{NH}_{2}$ and $\mathrm{CO}-\mathrm{NH}_{2}$, respectively, due to their comparable binding energies. Interestingly, the amount of oxygenated groups of MWCNT(plasma40) is higher than that of MWCNT(plasma300), which was supported by the results found in the previous study [28]. The study demonstrated that the lower the gas pressure, the higher the oxygen concentration. It appears highly likely due to the residual vacuum atmosphere of the plasma system. Additionally, plasma media at low pressures contain more ionized species in described system and typically provide a higher degree of surface functionalization.

$\mathrm{NH}_{3}$ plasma has been known to induce reduction along with nitrogen incorporation due to the presence of dissociated $\mathrm{H}$ species in the system, as stated in the study [29] involving nitrogen-doped reduced graphene oxide. However, the atomic percentage of nitrogen incorporated is less than $3 \%$ for both plasma treatments. Such low incorporation can arise from $\mathrm{C}-\mathrm{N}$ groups whose bonds may have been broken from the MWCNTs by a chemical attack in plasma [14]. Moreover, the discharge parameters such as the sample position in the reactor, treatment time, leaked gas pressure, and plasma power can significantly influence the number of functional groups created on MWCNTs $[28,30]$. Further to study the bonding states of nitrogen, $\mathrm{N} 1$ s peak located at a binding energy of around $400 \mathrm{eV}$ was deconvoluted for both MWCNT(plasma40) and MWCNT(plasma300), see Figure 3. Both spectra were fitted with two peaks: at 399 and $400 \mathrm{eV}$. In the case of plasma-treated MWCNT structures, the peak at lower binding energy was assigned as $-\mathrm{CO}-\mathrm{NH}_{2}$. The peak at $400 \mathrm{eV}$ was assigned to $-\mathrm{NH}_{2}$ bonds connected to the carbon in the lattice [17]. The relative intensity of the amide bonding states was slightly higher in the case of MWCNT(plasma40). The reason for this finding could be more chemical attacks of plasma reactive species on the MWCNT surface due to more collisions 


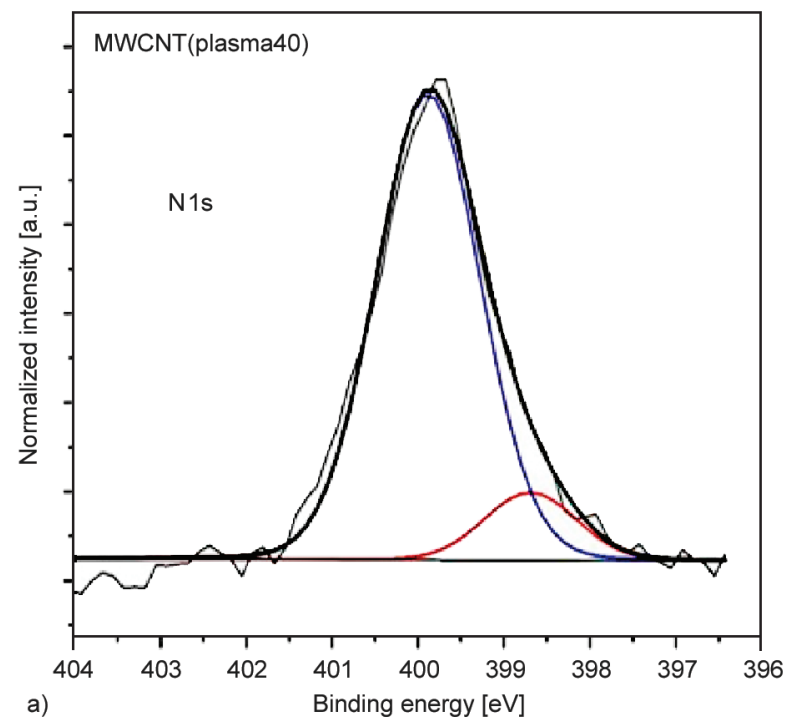

Figure 3. XPS deconvolution of HR N 1s peak for MWCNT

in the plasma medium at $300 \mathrm{~Pa}$ compared with $30 \mathrm{~Pa}$. However, quaternary-type nitrogen functionalities were absent on both samples [18].

\subsubsection{FTIR measurements}

FTIR spectra of pristine and plasma-treated MWCNT samples at various ranges are given in Figures 4. The peak at $3423 \mathrm{~cm}^{-1}$ of stretching vibrations of isolated surface- $-\mathrm{OH}$ moieties and/or - $\mathrm{OH}$ in carboxyl groups [31] in Figure 4a is shifted to higher and lower wavenumber in FTIR spectra of MWCNT(plasma40) and MWCNT(plasma300), respectively. In addition, $\mathrm{N}-\mathrm{H}$ stretching absorption peaks induced by ammonia plasma treatment appeared in the 3500$3300 \mathrm{~cm}^{-1}$ region [32], which could contribute to this shift. In the range of $2800-3000 \mathrm{~cm}^{-1}$ new $\mathrm{C}-\mathrm{H}$ peaks [33] have been seen in FTIR spectra of plasma-treated MWCNTs, which indicate that the opening of phenyl rings and their hydrogenation [29] occur during the plasma treatment. Plasma species such as ions, electrons, and radicals have the capacity to break the ordered structure of graphite/CNT,

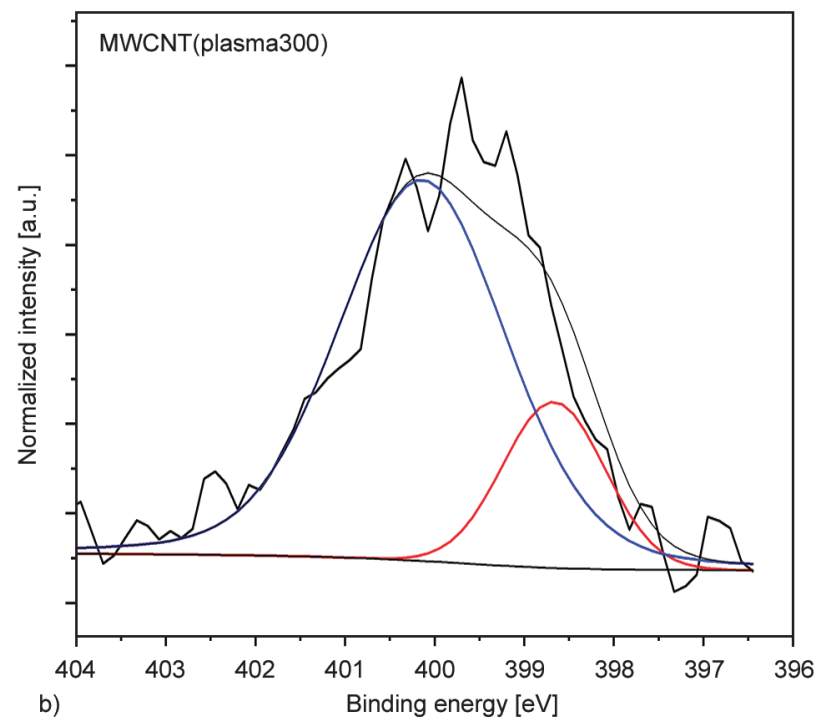

(a) plasma40 treated and (b) plasma300 treated samples.

favoring substitution reactions, breaking the aromaticity of the graphite rings, or generating defects and aliphatic fragments, as stated in the study [34]. The peaks at 1721, 1671, and $1592 \mathrm{~cm}^{-1}$ in the FTIR spectrum of pristine MWCNT sample in Figure 4b can belong to the carbonyl group of carboxylic acid/ ester, quinone group, and $\mathrm{C}=\mathrm{C}$ stretching, respectively [35]. The new peak of about $1630 \mathrm{~cm}^{-1}$ which could attribute to the carbonyl of the amide group [36], appears in FTIR spectra of the plasma-treated carbon nanotubes, confirming XPS finding in Figure 3. In contrast, the peak at $1721 \mathrm{~cm}^{-1}$ has no change after the plasma treatment, the one at $1671 \mathrm{~cm}^{-1}$ shifts to $1674 \mathrm{~cm}^{-1}$ for MWCNT(plasma300). The $\mathrm{C}=\mathrm{C}$ is stretching at $1592 \mathrm{~cm}^{-1}$ shifts to 1590 and $1575 \mathrm{~cm}^{-1}$ in order of MWCNT(plasma40) and MWCNT(plasma300) due to the coupling of the peaks of $-\mathrm{NH}_{2}$ and $\mathrm{C}=\mathrm{C}$ vibrations [37]. The shift is more in the case of MWCNT(plasma300).

The peaks between 1000 and $1250 \mathrm{~cm}^{-1}$ in Figure $4 \mathrm{c}$ can belong to the $\mathrm{C}-\mathrm{O}$ group of ether/alcohol/ester molecules [38] and the $\mathrm{C}-\mathrm{N}$ group of amine/amide

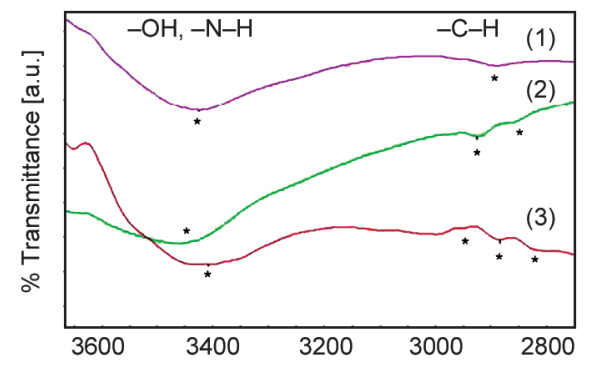

a)

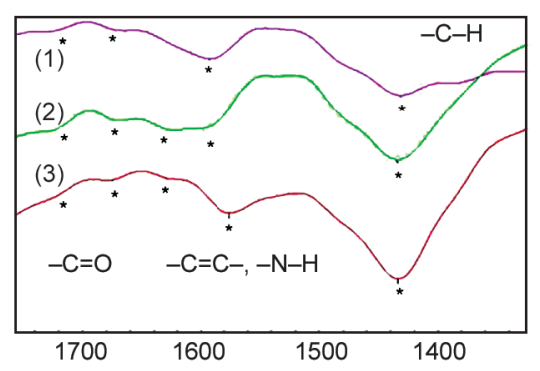

b)

Wavenumbers $\left[\mathrm{cm}^{-1}\right]$

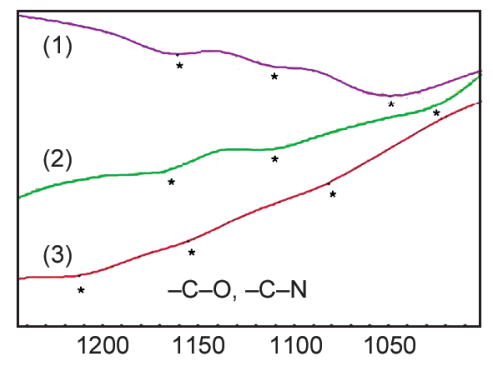

c)

Figure 4. FTIR spectra of pristine MWCNT (1), MWCNT(plasma40) (2) and MWCNT(plasma300) (3) samples in the ranges of $2800-3600 \mathrm{~cm}^{-1}$ (a), $1300-1700 \mathrm{~cm}^{-1}$ (b) and $1000-1250 \mathrm{~cm}^{-1}$ (c). 
molecules [39]. These peaks of pristine MWCNT sample shift to lower $(\mathrm{C}-\mathrm{O})$ or higher wavenumber (C-N) for MWCNT(plasma40). The peaks at 1040 and $1115 \mathrm{~cm}^{-1}$ couple at $1081 \mathrm{~cm}^{-1}$, and a new peak is observed at $1212 \mathrm{~cm}^{-1}$ in the FTIR spectrum of MWCNT(plasma300).

In the case of $\mathrm{NH}_{3}$ plasma, the dissociation of the feeding gas can give rise to various reactive species such as atomic hydrogen, $\mathrm{NH}_{\mathrm{x}}$ species $(x=1-3)$, atomic and molecular nitrogen, excited nitrogen molecules, and ions. To understand the probable effects of each of the species mentioned above on carbon nanotubes, we can find in literature mainly two possible reactions. One is the reduction of the oxygen functionalities due to the reducing atmosphere in the system due to dissociated hydrogen atoms. Hydrogen radicals gave dissociation energies for oxygen functional groups, which are capable of reducing graphene oxide [40]. Hydroxyl radicals have the property of electrophilic addition as well as oxidation of CNTs [41]. Energetic $\mathrm{N}_{2}^{+}$ions approaching a surface are also able to undergo resonance neutralization in which an electron from the surface tunnels through the potential barrier between the solid and ion to populate a resonant level in the ion [28]. Then plasma-excited nitrogen is reacted with surface $\mathrm{OH}$ groups on the surface and produce $\mathrm{NH}_{\mathrm{x}}$ [42]. Another possibility is the formation of amine and amide functional groups by the reaction between carbon atoms of the lattice with the plasma particles.

When the findings obtained from Figure 4 are combined with Figures 2 and 3, it could be said that i) some carboxyl groups reduce to new structures involving $\mathrm{C}=\mathrm{O}$ and $\mathrm{C}-\mathrm{OH}$ groups, ii) the $\mathrm{C}-\mathrm{OH}$

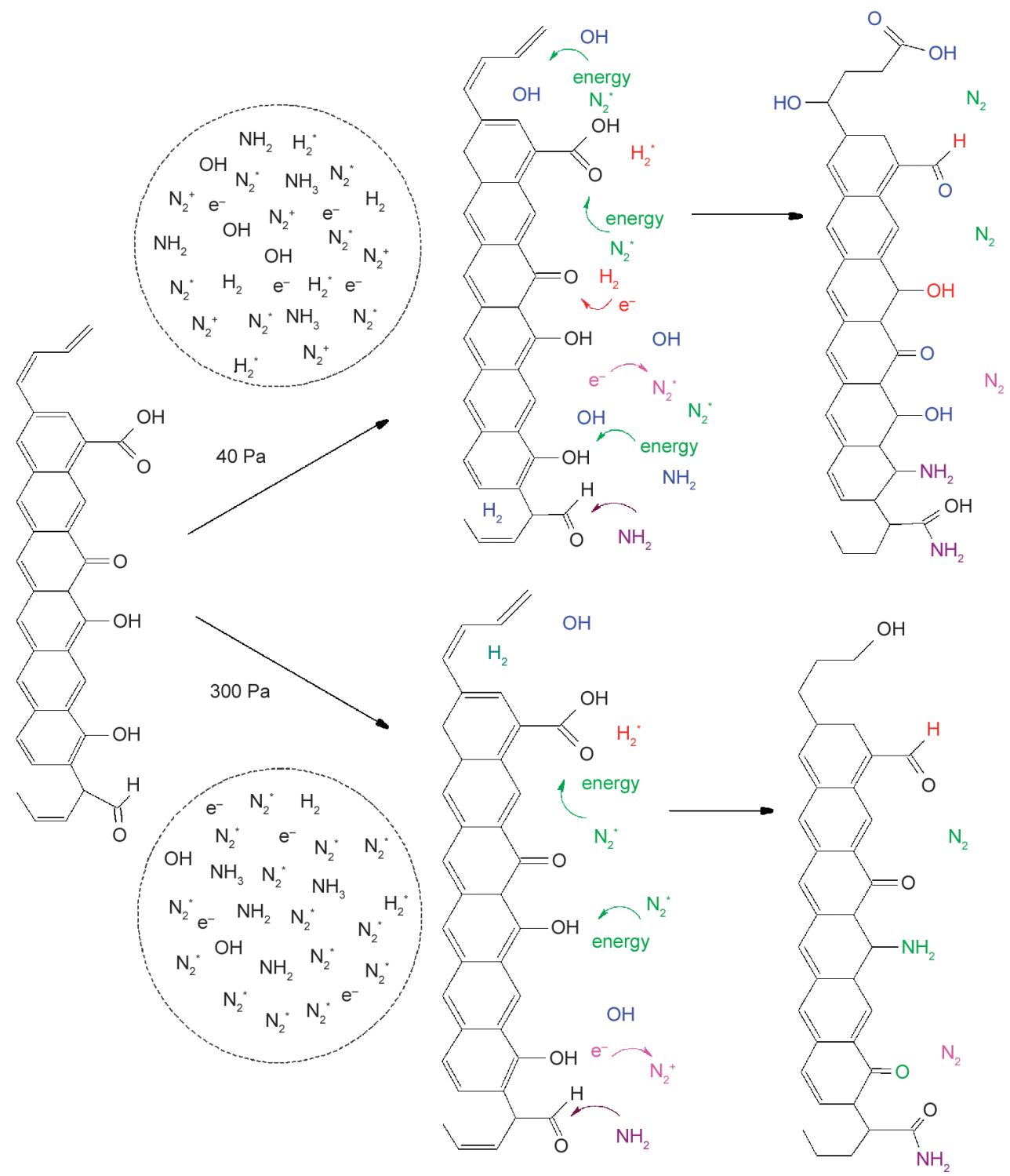

Figure 5. Possible reactions of CNT surface with various species in ammonia plasma media at 40 and $300 \mathrm{~Pa}$. 
groups oxidized to new carbonyl groups, iii) new kind of $\mathrm{C}-\mathrm{O} / \mathrm{C}-\mathrm{N}$ groups also occur as a result of the reactions, iv) the hydroxyl/carbonyl groups react with amidogen radicals [43] to yield amine/amide groups, v) various $\mathrm{C}-\mathrm{H}_{\mathrm{x}}$ species including $-\mathrm{CH}_{3}$ on the sidewalls and $\mathrm{sp}^{3} \mathrm{CH}_{2}$ species (alcohol) form likely at the defect sites and ends of carbon nanotubes inconsequence of reducing of carboxyl groups [44]. Based on mentioned studies and findings above, some of the possible reactions of the carbon nanotube surface with the reactive plasma species can be presented as outlined in Figure 5.

\subsection{Epoxy}

TEA functions as an initiator for epoxy resin homopolymerization, while the anhydride (HMPA) acts as a comonomer in the polymerization process, see a structural scheme of reactions in Figure 6a.

The clues on occurring reactions can be seen from FTIR spectra of epoxy resin (DGEBA), curing agent (HMPA), and epoxy matrix shown in Figure 6b. The formation of the new ester bonds is observed in the FTIR spectrum of the epoxy matrix, which confirms the reaction between the oxirane ring of DGEBA at about $913 \mathrm{~cm}^{-1}$ and the carbonyl groups o HMPA at 1788 and $1860 \mathrm{~cm}^{-1}$. Whereas the $\mathrm{C}-\mathrm{O}$ deformation band of the oxirane group almost disappears in the spectrum of the epoxy matrix. The changes in peaks at the range of $1000-1250 \mathrm{~cm}^{-1}$ are also observed for epoxy matrix and are assigned to $\mathrm{C}-\mathrm{O}$ stretching [45].

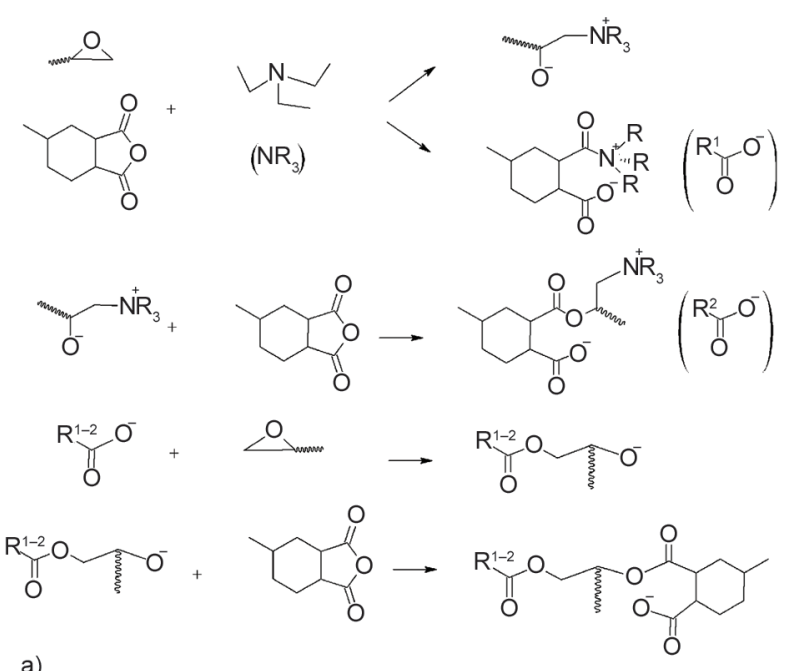

\subsection{Epoxy composites filled with MWCNTs 3.3.1. FTIR measurements}

The interactions of the MWCNTs with HMPA and DGEBA were examined by using FTIR measurements with a resolution of $0.4 \mathrm{~cm}^{-1}$. The findings of the FTIR spectra of the interactions of pristine and MWCNT(plasma300) samples with DGEBA were summarized in Table 1. The stretches of $\mathrm{C}-\mathrm{H}$ $\left(3056 \mathrm{~cm}^{-1}\right)$, of $\mathrm{C}-\mathrm{O}\left(913 \mathrm{~cm}^{-1}\right)$, of $\mathrm{C}-\mathrm{O}-\mathrm{C}$ of oxirane $\left(829 \mathrm{~cm}^{-1}\right)$ group, and of ether $\left(1033 \mathrm{~cm}^{-1}\right)$ in DGEBA shift to more wavenumbers in the case of the interaction of plasma-treated MWCNTs with DGEBA. It is obvious that the plasma treatment improved the interactions between MWCNTs and DGEBA.

Table 1 also displays that the interaction of pristine with HMPA causes more shift of the peaks corresponding to $\mathrm{C}=\mathrm{O}$ stretching of anhydride group in the structure of HMPA than plasma-treated ones. The reason for this could be repelling force between the carbonyl group in HMPA and the ones in carboxyl/amide/quinone structures in plasma-treated MWCNTs.

Carboxyl, alcohol, and amine groups on the surface of MWCNTs could potentially participate in the reaction with epoxy as another curing agent. These reactions can result in secondary alcohols, which further react with DGEBA or HMPA to give $\beta$-hydroxy ether and diester, respectively [46]. In the case of pristine MWCNT samples, oxygen-containing functional groups could be involved in such reactions.

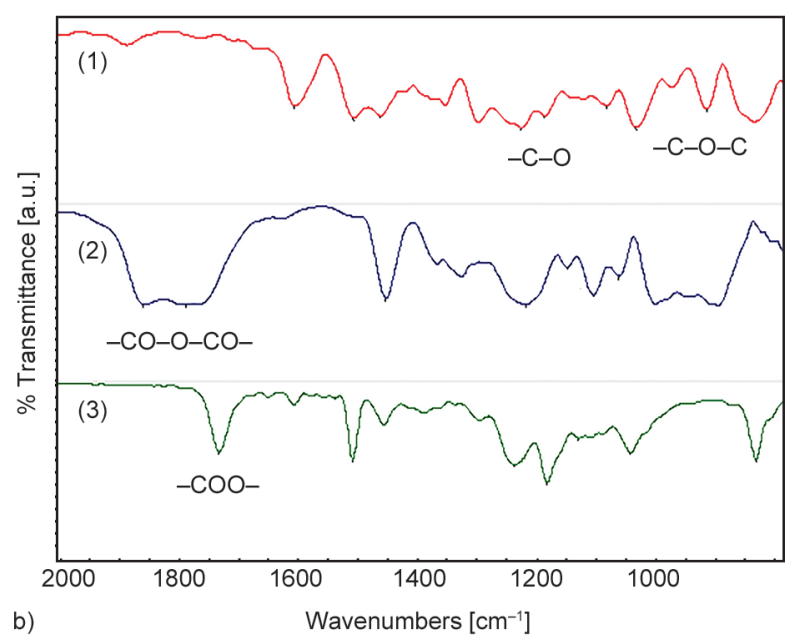

(b) FTIR spectra of DGEBA (1), HMPA (2), and epoxy

Figure 6. (a) Possible reactions of epoxy polymerization, matrix (3) (b). 
Table 1. The findings on FTIR spectra of the interactions of HPMA/DGEBA with the fillers.

\begin{tabular}{|l|c|c|c|c|c|c|}
\hline \multirow{2}{*}{ The interactions of the components } & \multicolumn{7}{|c|}{$\begin{array}{c}\text { Wavenumbers } \\
\text { [cm-1] }\end{array}$} \\
\cline { 2 - 8 } & $\begin{array}{c}\text { Asym- } \\
\text { carbonyl }\end{array}$ & $\begin{array}{c}\text { Sym- } \\
\text { carbonyl }\end{array}$ & $\begin{array}{c}\text { CH of } \\
\text { oxirane ring }\end{array}$ & $\begin{array}{c}\text { C-O-C of } \\
\text { ethers }\end{array}$ & $\begin{array}{c}\text { C-O of } \\
\text { oxirane }\end{array}$ & $\begin{array}{c}\text { C-O-C of } \\
\text { oxirane }\end{array}$ \\
\hline HMPA/DGEBA & 1858.3 & 1784.3 & 3055.7 & 1032.6 & 913.5 & 829.5 \\
\hline MWCNT-HMPA/DGEBA & 1860.2 & 1785.5 & 3056.2 & 1034.7 & 915.8 & 832.3 \\
\hline MWCNT(plasma40)-HMPA & 1859.6 & 1784.5 & - & - & - & - \\
\hline MWCNT(plasma300)-HMPA/DGEBA & 1858.3 & 1784.0 & 3059.3 & 1035.7 & 916.2 & 835.3 \\
\hline
\end{tabular}

Table 2. The findings of FTIR spectra of the epoxy/epoxy composites.

\begin{tabular}{|l|c|c|c|c|c|}
\hline \multirow{2}{*}{\multicolumn{1}{c|}{ Materials }} & \multicolumn{5}{c|}{$\begin{array}{c}\text { Wavenumbers } \\
{\left[\mathbf{c m}^{-1}\right]}\end{array}$} \\
\cline { 2 - 6 } & $-\mathbf{O}-\mathbf{C}=\mathbf{O}$ & $-\mathbf{C}=\mathbf{C}-,-\mathbf{C}=\mathbf{O}$ & $-\mathbf{C}-\mathbf{N}-,-\mathbf{C}-\mathbf{O}-$ & $-\mathbf{C}-\mathbf{N}-,-\mathbf{C}-\mathbf{O}-$ & $-\mathbf{C}-\mathbf{N}-,-\mathbf{C}-\mathbf{O}-$ \\
\hline Epoxy resin & 1734.1 & 1607.9 & 1235.9 & 1181.8 & 1041.3 \\
\hline MWCNT-Epoxy0.4\% & 1735.2 & 1607.2 & 1232.5 & 1182.9 & 1032.6 \\
\hline MWCNT(plasma40)-Epoxy0.4\% & 1734.9 & 1606.1 & 1233.0 & 1183.1 & 1034.5 \\
\hline MWCNT(plasma300)-Epoxy0.4\% & 1735.1 & 1605.9 & 1231.9 & 1182.9 & 1033.9 \\
\hline
\end{tabular}

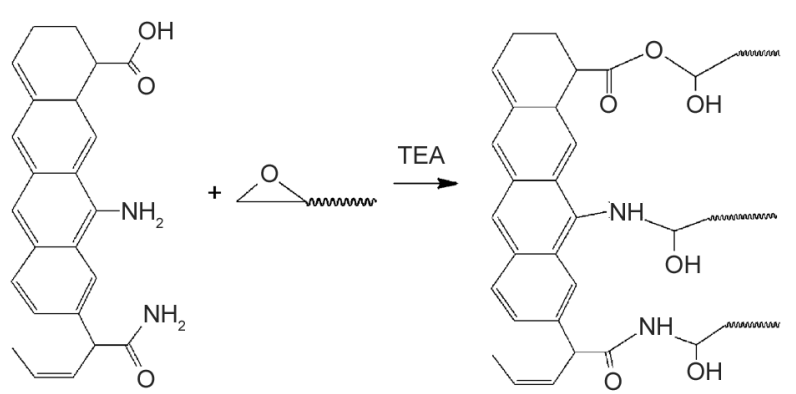

Figure 7. Possible reactions between DGEBA and the functional groups on the MWCNTs.

On the other hand, both oxygen and nitrogen-containing functional groups on MWCNTs could give reaction with epoxy in the presence of TEA in Figure 7 while using plasma modified samples, based on results from XPS and FTIR analysis. If the functionalization degree is larger, the carboxyl/amine/ amide groups linked to the MWCNT surface can participate in the curing reaction to a greater extent [47]. Considering the findings of FTIR spectra of the epoxy composites in Table 1 in terms of the reactions, some changes on the wavenumbers of $-\mathrm{C}-\mathrm{O}-,-\mathrm{C}-\mathrm{N}-$, $\mathrm{C}=\mathrm{O}$ and ester groups have been seen. The changes may confirm the reactions because of the overlapping of some peaks assigned to the bonds formed during the reactions between the fillers and the components and the ones between all components.

\subsubsection{Morphology characterization}

The dispersion state of the MWCNTs in the epoxy matrix at different scales was studied by examining the cross-section fracture surfaces after the complete fracture failure during tensile testing over the ultimate strain from SEM micrographs. During the tensile test, MWCNTs, which were intertwined with each other and with epoxy segments, were straightened longitudinally, and their mutual mechanical bonds decreased. Then in the plane of the composite fracture, the brittle MWCNTs broke or were released from epoxy molecular segments. SEM micrographs of the composite fracture are shown in Figures 8a$8 \mathrm{c}$. The broken and pulled-out MWCNTs, which protruded from the plane of the cross-section (bright spots on the surface), are clearly visible in Figure 8c. A similar structure involving the clusters and high fracture surface roughness was observed for the epoxy composites in previous studies [15, 48]. It was stated that the change in the surface of the fracture crosssection from smooth to rough indicates an increase in energy required for fracture, suggesting a reinforcing effect [15].

SEM micrographs of the epoxy and the areas with the clusters at cross-section fracture surfaces of the epoxy composites in Figure 9 show differences in the number of islets formed at fractured surfaces and, therefore, in their surface areas. While the epoxy has less islet number compared to its composites, MWCNTEpoxy $0.2 \%$ composite has less islet number than MWCNT(plasma300)-Epoxy0.2\%. MWCNT(plasma300)-Epoxy $0.4 \%$ has the highest number of islets. The number or surface area of these islets may provide information on the resistance to rupture and the strength of the interaction between the MWCNTs 


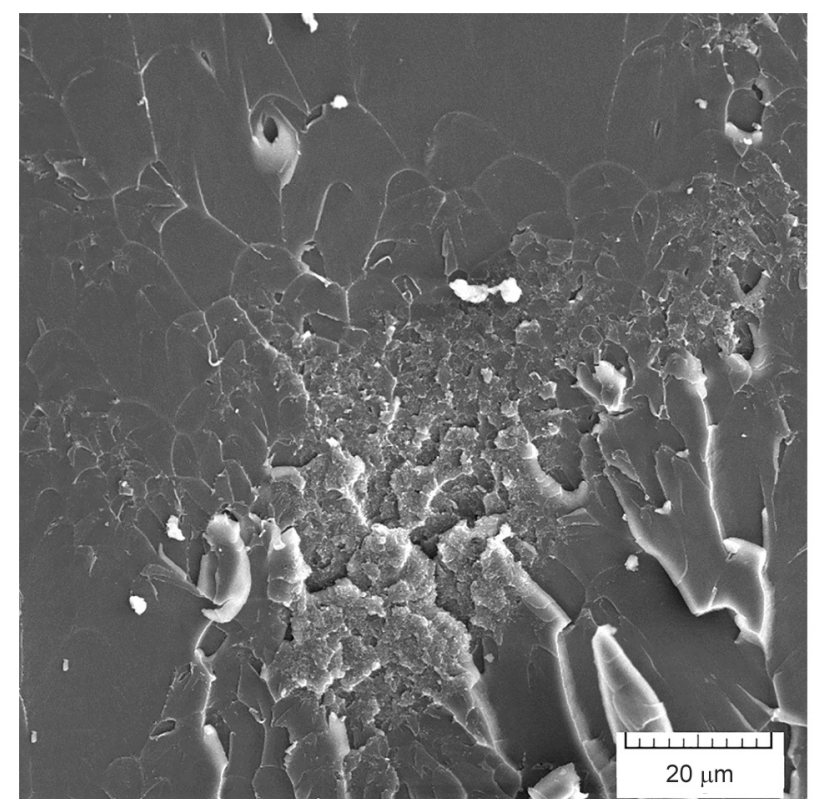

a)

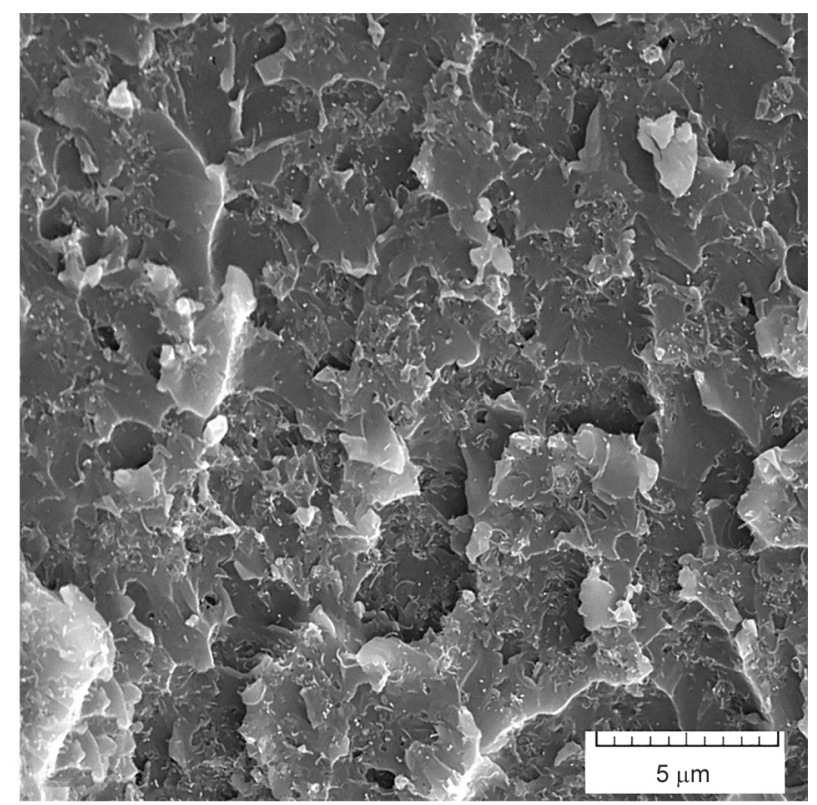

b)

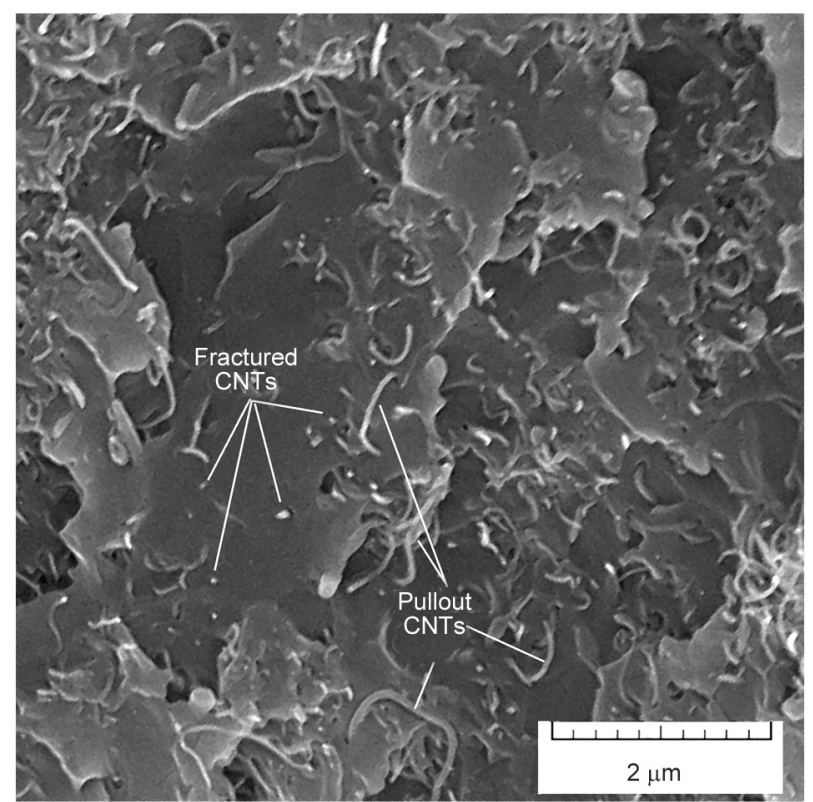

c)

Figure 8. SEM micrographs of the cross-section fracture surface after complete fracture failure during tensile testing of MWCNT(plasma40)-Epoxy0.2\% for different scales $20 \mu \mathrm{m}$ (a), $5 \mu \mathrm{m}$ (b) and $2 \mu \mathrm{m}$ (c).

and epoxy resin in the composites. In addition, it was stated in another study [49] that the formation of holes on the fractured surface indicated the poor interfacial bonding between MWCNTs and epoxy resin. No obvious holes mean that most nanotubes are embedded tightly in the matrix, indicating the most nanotubes are broken instead of pullout during fracture. According to this interpretation, plasma-treated MWCNTs can react with the epoxy better than pristine ones at the areas with the clusters, as given in Figure 9. In addition, the surface treatment with ammonia plasma can add mutual electrostatic repulsion charges to the surface of the CNTs, which gives the CNTs the potential to overcome the binding van der Waals forces and aid dispersion [50].

\subsubsection{The measurements on cure behavior of the composites}

The C.D. value of the pure epoxy matrix is $96.7 \%$. Table 2 shows that the pristine and plasma-treated MWCNTs (0.2\%) induce epoxy composites with a lower cure degree than the pure epoxy matrix. The C.D. value decreases with the increase in MWCNTs loading for the epoxy composites. 


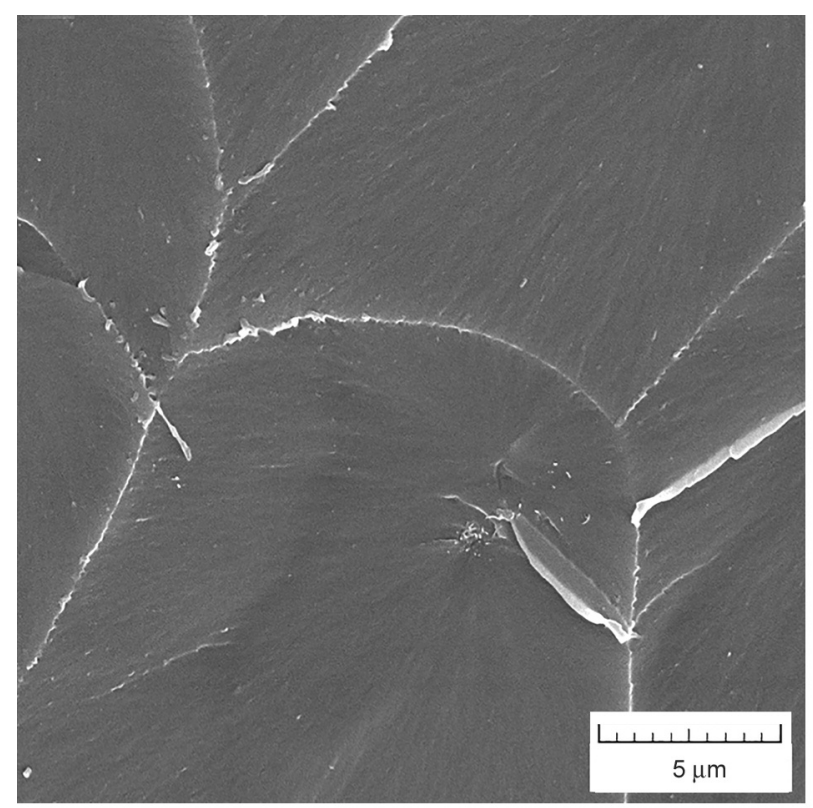

a)

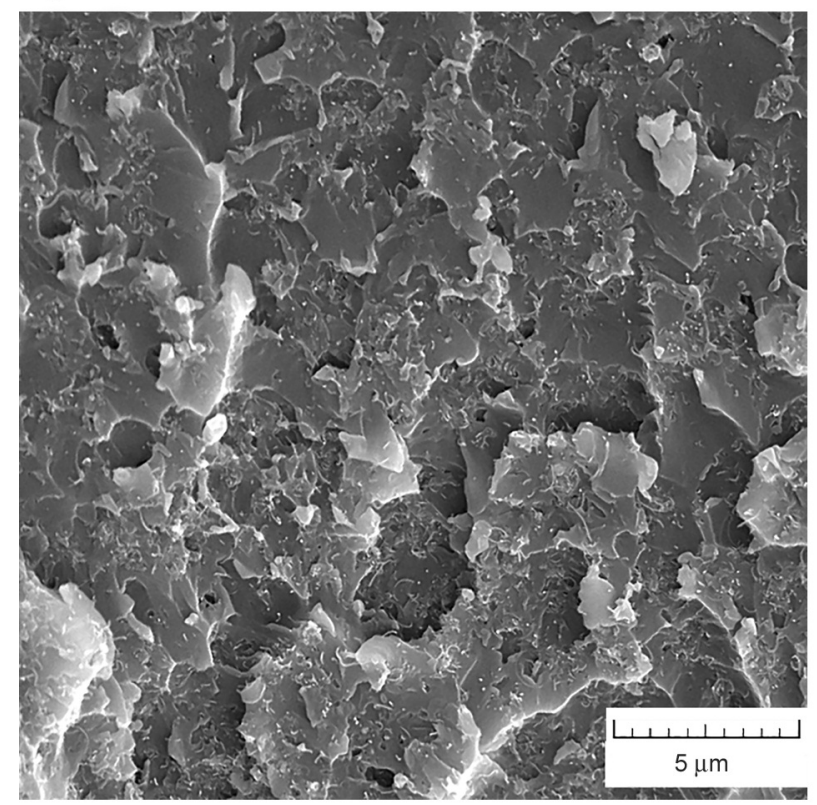

c)

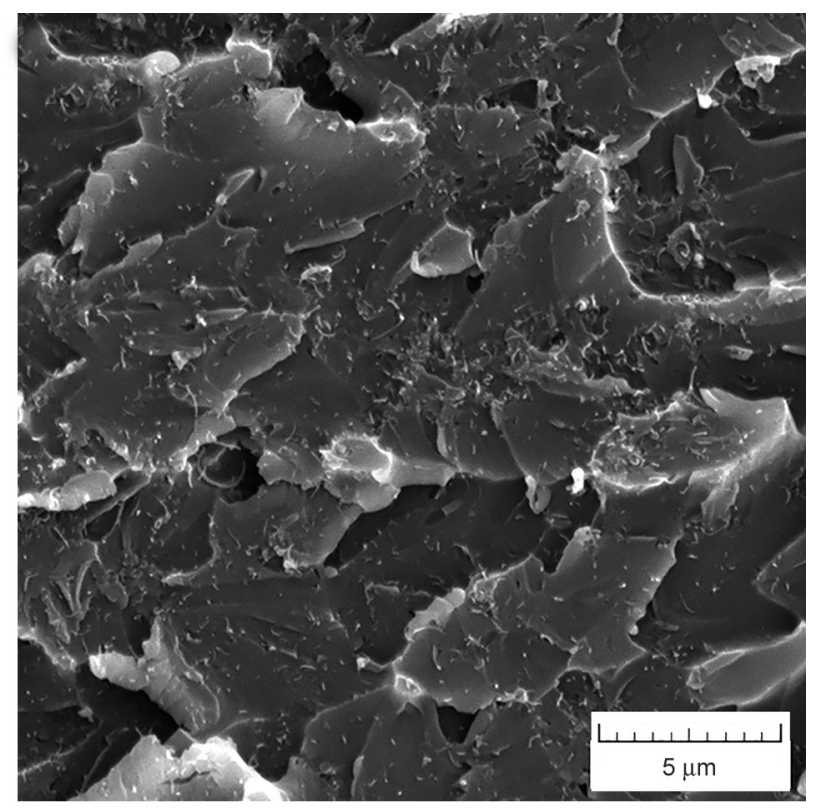

b)

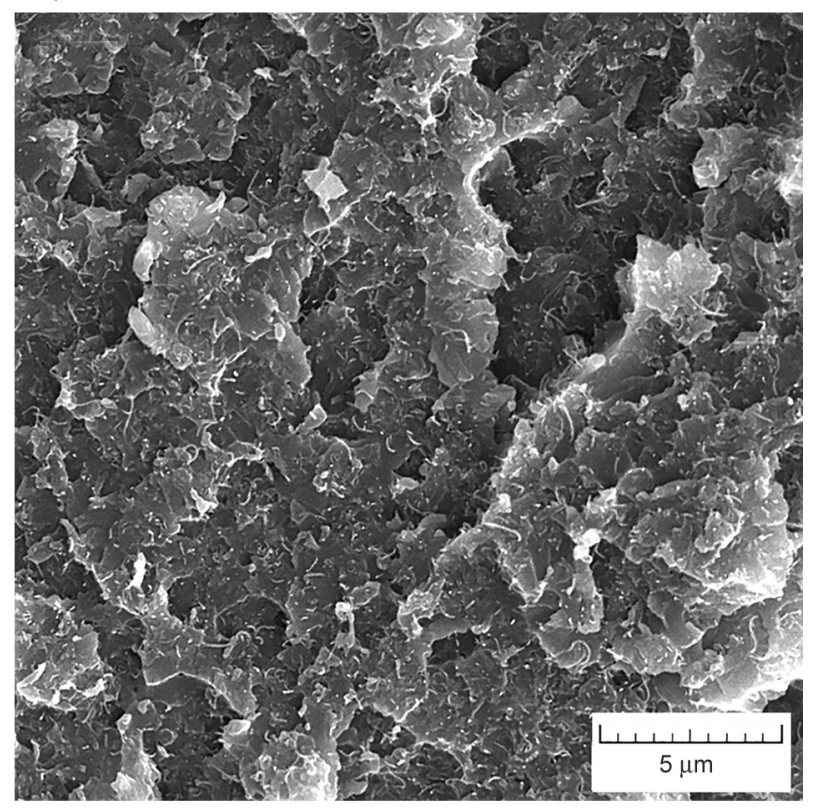

d)

Figure 9. Sample SEM micrographs of cross-section fracture surfaces after the complete fracture failure during tensile testing of Epoxy (a), the regions with the clusters at cross-section fracture surfaces of MWCNT-Epoxy0.2\% (b), MWCNT(plasma40)-Epoxy0.2\% (c), MWCNT(plasma300)-Epoxy0.4\% (d).

Table 3. The properties of the resulting epoxy materials.

\begin{tabular}{|l|c|c|c|c|}
\hline \multicolumn{1}{|c|}{ Epoxy materials } & $\begin{array}{c}\text { Loading } \\
{[\mathbf{\%}]}\end{array}$ & $\boldsymbol{C . D .}$ & $\begin{array}{c}\boldsymbol{T}_{\mathbf{g}} \\
{\left[{ }^{\circ} \mathbf{C}\right]}\end{array}$ & $\begin{array}{c}\boldsymbol{E} \\
{[\mathbf{G P a}]}\end{array}$ \\
\hline Epoxy resin & 0 & 96.7 & 114.7 & 1.99 \\
\hline \multirow{2}{*}{ MWCNT-Epoxy } & 0.2 & 90.3 & 114.1 & 2.07 \\
\cline { 2 - 5 } & 0.4 & 87.9 & 112.8 & 2.15 \\
\hline $\begin{array}{l}\text { MWCNT(plasma40)- } \\
\text { Epoxy }\end{array}$ & 0.2 & 89.4 & 112.9 & 2.36 \\
\cline { 2 - 5 } & 0.4 & 87.9 & 105.5 & 2.41 \\
\hline $\begin{array}{l}\text { MWCNT(plasma300)- } \\
\text { Epoxy }\end{array}$ & 0.2 & 88.8 & 113.9 & 2.20 \\
\cline { 2 - 5 } & 0.4 & 87.8 & 109.8 & 2.28 \\
\hline
\end{tabular}

The cure enthalpy change ( $\left.\Delta H_{\text {cure }}\right)$ values of the epoxy resin were found as $-296.6 \mathrm{~J} / \mathrm{g}$, while those of the epoxy composites (MWCNT-Epoxy0.2\%: $-265.7 \mathrm{~J} / \mathrm{g} ; \quad$ MWCNT(plasma40)-Epoxy0.2\%: $252.8 \mathrm{~J} / \mathrm{g} ; \quad$ MWCNT(plasma300)-Epoxy0.2\%: $-248.52 \mathrm{~J} / \mathrm{g}$ ) were lower than this value. Due to different variables (loading amount, aspect ratio of CNTs, the amount of and the type of functional groups attached to CNTs, etc.) that can interfere in the curing reaction of the composites, the trend of change 
in the cure enthalpy of the epoxy composites with CNTs varies in the literature [47]. The decrease in $\Delta H_{\text {cure }}$ values supports the decrease in the C.D. values of the epoxy composites. This finding has also been observed in previous studies for the epoxy composites with chemically modified CNTs [26, 51, 52]. de Simone Cividanes et al. [48] examined the influence of CNTs on the curing process of epoxy resin in many studies. Among the explanations in the studies, they stated that dispersion homogeneity seems to be a decisive factor that will determine the curing reaction rate of the epoxy/CNT composites. In our case, the heterogeneity in the dispersion of MWCNTs in Figure 8 slows down the rate of epoxy resin cure and reduces the heat curing reaction. The cure behavior of an epoxy resin can be divided into two stages, depending on the previous study [53]. The first one is in which the reaction is chemically controlled, and the second one is in which diffusion dominates due to phenomena of gelation and vitrification. In the early stage, the reaction is initiated by any hydrogen bond donor molecules, which can be moisture or impurities. In the last stage, the viscosity of the mixture increases significantly, and the reaction is diffusion-controlled. The dispersion of MWCNTs is crucial in both stages.

\subsubsection{The relations among elastic modulus, glass transition temperatures, and C.D. values}

Elastic moduli of epoxy and epoxy composites were determined from the slope of the stress-strain lines, as shown in Figure 10. The resulting elastic modulus of Epoxy, MWCNT-Epoxy0.2\%, MWCNTEpoxy0.4\%, MWCNT(plasma300)-Epoxy0.2\% and MWCNT(plasma300)-Epoxy0.4\% was 1.99, 2.07, $2.15,2.20$ and $2.28 \mathrm{GPa}$, respectively.

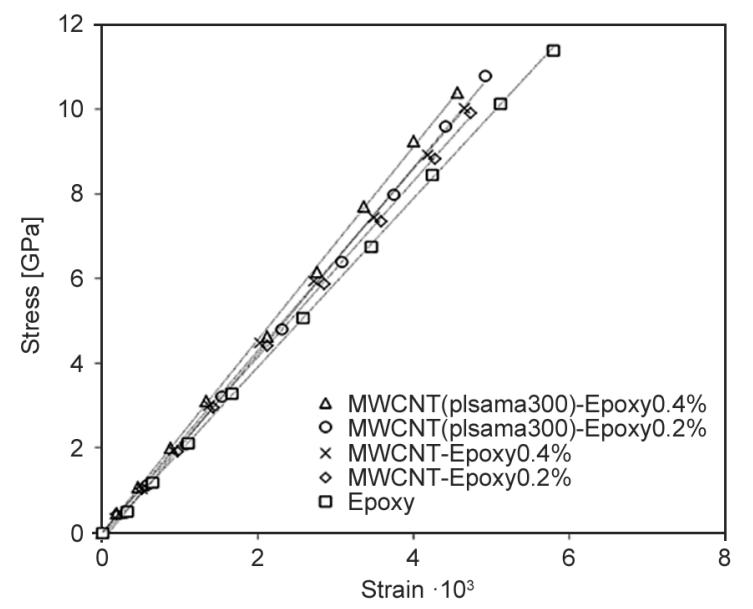

Figure 10. The stress-strain graph is used to determine the elastic modulus of the materials.
Table 2 also shows the relations among $T_{\mathrm{g}}, E$, and C.D. [\%] values of the epoxy composites. An increase in elastic modulus with a decrease in $T_{\mathrm{g}}$ values is seen in all composites in comparison with epoxy resin. A similar observation was seen in the epoxy composites with MWCNTs functionalized with RF plasma in $\mathrm{Ar} / \mathrm{O}_{2}$ and $\mathrm{Ar} / \mathrm{O}_{2} / \mathrm{N}_{2}$ atmospheres [14]. MWCNT(plasma40)-Epoxy $0.4 \%$ sample shows the highest increment in the elastic modulus, approximately $21 \%$ compared with the epoxy and $12 \%$ compared with the MWCNT-Epoxy $0.4 \%$ according to Table 2. Many studies have shown that the incorporation of low amounts of amino-functionalized CNTs into the epoxy matrix can greatly enhance mechanical properties, as stated in the study of Chen et al. [16]. Despite the MWCNT clusters observed in the epoxy composites in Figure 8, the increase in elastic modulus was explained that the agglomerates provide higher apparent filler loading and trap polymer in the void space between MWCNTs [9]. The fact that plasma-treated MWCNTs interact further with epoxy shows the MWCNTs trap more epoxy in the spaces between them, confirmed by the magnified SEM images of the region with the clusters in Figure 9 and the findings in Table 1. This explains the increase observed in the elastic modulus.

$T_{\mathrm{g}}$ of pure epoxy matrix with cure degree $96.7 \%$ is about $115^{\circ} \mathrm{C}$ according to Table 2 . The decrease is observed in $T_{\mathrm{g}}$ values of the epoxy composites with the decrease in C.D. values of the composites. MWCNT(plasma40)-Epoxy0.4\% sample has lowest $T_{\mathrm{g}}$ value among the composites. The addition of MWCNTs to epoxy system influences the stoichiometric ratio of the resin/hardener reaction for vicinal MWCNTs, acting as steric limitations near interfaces or changing the formation of the crosslinked network. As result of this, the MWCNTs could cause a reduction of the intermolecular forces between the epoxy polymer chains, pulling the chains apart. The reduction of the intermolecular forces as well as that of cure degree increase the mobility of the chains and consequently induce the decrease in $T_{\mathrm{g}}$ values of the composites [14]. The plasma-treated samples could interact further with DGEBA compared with pristine one due to more functional groups on it, blocking the reaction sites in the epoxy monomer [54]. It means that the plasma treatment provides a better-dispersed system for epoxy, hindering more dominantly the curing reaction $[14,55]$. In addition, it was stated in [56] that ultrasonication treatment 
could cause a decrease in $T_{\mathrm{g}}$ of neat epoxy when the resin was processed using it. According to a previous study [57], there is a competition between two group effects that cause the decrease or increase in $T_{\mathrm{g}}$ values of epoxy composites with increasing MWCNT loading. In the first group effects, there is the decreasing crosslinking density due to extra volume imposed by large MWCNT-epoxy interface and agglomeration of nanotubes with no causing restriction on epoxy mobility. The second group includes the physical hindrance of MWCNTs to the mobility of epoxy matrix and high crosslinking degree due to the accelerating effect of MWCNT at the initial curing state. In our case, the first group effects could be more prominent on $T_{\mathrm{g}}$ values of the epoxy composites.

\subsection{Practical use of the MWCNT-epoxy composite}

\subsubsection{Effect of volatile organic compounds on the} reflection coefficient of a microstrip sensor

To demonstrate a possible use of MWCNT(plasma300) filled epoxy $0.4 \%$ composites, a microstrip resonant vapor sensor was assembled that was used to detect the occurrence of volatile organic compounds (VOCs) and to monitor the ambient temperature. The sensing mechanism of the sensor was based on changes in its reflection coefficient, which indicates how much of an electromagnetic wave is reflected by MWCNT-Epoxy microstrip impedance affected by VOC adsorption. Details on the initial design and original use of microstrip resonant vapor sensors with microstrips made of thermoplastic ethyleneoctene copolymer matrix and embedded MWCNTs are given in our recent paper [58].

The schematic and the photo in Figure 11 shows how the MWCNT-Epoxy composite strip $(40 \times 8 \mathrm{~mm}$ and thickness of $2.5 \mathrm{~mm}$ ) and was attached to a dielectric poly(methyl methacrylate) plate (Polycasa,
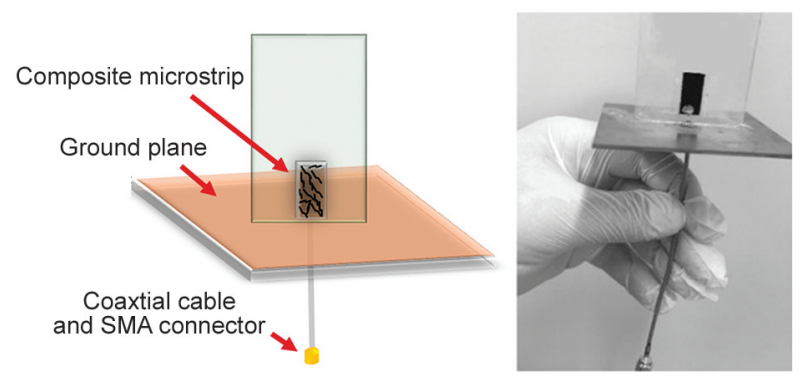

Figure 11. A schematic illustration and a photo of the microstrip resonant vapor sensor with the microstrip made of MWCNT(plasma300)-Epoxy $0.4 \%$ composite. s.r.o., Pribram, Czech Republic) of $60 \times 70 \mathrm{~mm}$ and thickness of $1.5 \mathrm{~mm}$. The ground plane of the sensor was made from a Flame Retardant 4 (FR-4) epoxy substrate covered with copper $(105 \times 105 \mathrm{~mm})$ with dielectric constant $\varepsilon_{\mathrm{r}}=4.4$. The thickness of the substrate was $1.6 \mathrm{~mm}$.

The principle of measuring the occurrence of VOCs is based on their adsorption by a composite microstrip, which changed its electrical resistance, impedance, and consequently, the reflection coefficient (RC) spectrum. To assess the RC spectrum affected by VOCs under experimental conditions, the sensor with the composite microstrip was placed into a chamber filled with a saturated vapor of a respective VOC liquid at a temperature of $25^{\circ} \mathrm{C}$. After exposure to the given vapor for the predetermined time ensuring complete vapor adsorption into the composite microstrip within $120 \mathrm{~s}$, the power reflected from the sensor was assessed in the range from $2 \mathrm{MHz}$ to $4 \mathrm{GHz}$ by the N9912A FieldFox Handheld RF spectrum analyzer (Keysight Technologies, Santa Rosa, CA, USA) and quantified by the sensor reflection coefficient. The desorption time was also $120 \mathrm{~s}$. Additional details on the measurement procedure used are in our paper [58].

In the initial state prior to vapor exposure, there were three reductions in the reflection coefficient spectrum at frequencies of about $2.85,3.35$, and $3.75 \mathrm{GHz}$ (Figure 12). Upon exposure to acetone (polarity index 5.1, the Hildebrand solubility parameter $19.9 \mathrm{MPa}^{1 / 2}$, the saturated vapor pressure $30.6 \mathrm{kPa}$ at $25^{\circ} \mathrm{C}$ ), propanol (polarity index 4.0, the Hildebrand solubility parameter $23.8 \mathrm{MPa}^{1 / 2}$, the saturated vapor

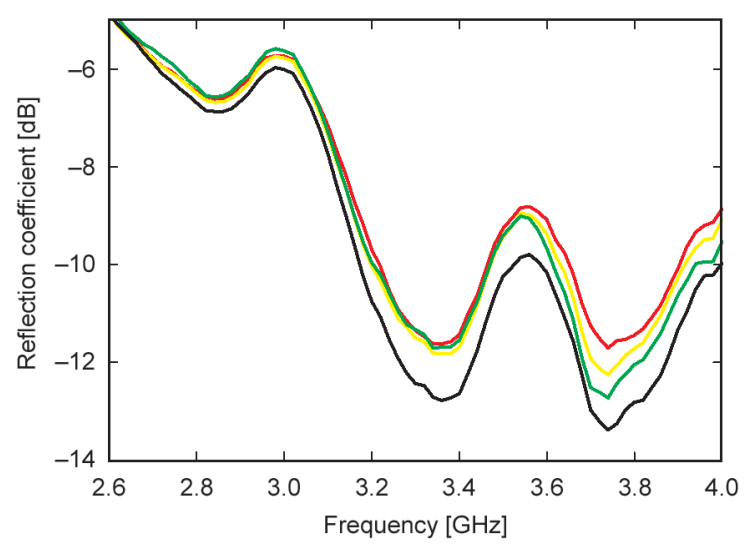

Figure 12. The reflection coefficient spectrum of the MWCNT(plasma300)-Epoxy microstrip resonant sensor prior to vapor exposure (-) and after exposure to saturated vapors of acetone (-), propanol (-), and xylene (-) for $120 \mathrm{~s}$. 
pressure $2.7 \mathrm{kPa}$ at $25^{\circ} \mathrm{C}$ ) and xylene (polarity index 2.5 , the Hildebrand solubility parameter $18.2 \mathrm{MPa}^{1 / 2}$, the saturated vapor pressure $\approx 1 \mathrm{kPa}$ at $25^{\circ} \mathrm{C}$ ), the reflection coefficient spectra have shifted above the base spectrum of the resonator-based composite sensor unaffected by the vapors in the frequency range from 2.6 MHz to $4 \mathrm{GHz}$. No differences were found in the spectra affected or unaffected by the vapors at frequencies below $2.6 \mathrm{GHz}$.

According to the results in Figure 12, the resonatorbased MWCNT-Epoxy composite sensor clearly detected the occurrence of VOCs. Due to the differences in the values of the reflection coefficient of VOCs at a frequency of $3.75 \mathrm{GHz}$, this separate response of the microstrip resonant sensor can be employed to detect an occurrence of a particular vapor. In this particular case, vapors of acetone (red line), propanol (pink line), and xylene (blue line) can be distinguished. The increase in the reflection coefficient from the initial value prior to vapor exposure is greatest for the frequency $3.75 \mathrm{GHz}$ for acetone with the highest saturated vapor pressure $30.6 \mathrm{kPa}$ at $25^{\circ} \mathrm{C}$ and polarity index 5.1 of all vapors used. The value of the increase of the reflection coefficient is lower for propanol with lower saturated vapor pressure and polarity index than acetone. The lowest value of the increase in the reflection coefficient is then for xylene with the lowest saturated vapor pressure and polarity index of all three vapors used.

\subsubsection{Effect of temperature on the reflection coefficient of an MWCNT-epoxy composite microstrip sensor}

A more elastic composite, which requires greater stress to deform (Figure 10), indicates an interlocking of MWCNTs into an epoxy matrix. An interconnected network of epoxy segments is created during the epoxy curing process. Intensive molecular interactions between chemical groups on the carbon nanotube surface, epoxy, and the curing agent may participate in the curing reaction (Section 3.3.), leading to a higher crosslinking density. If the MWCNT(plasma300)-Epoxy $0.4 \%$ composite is exposed to temperature changes, the changing temperature initiates a corresponding volume and MWCNT arrangement variation due to MWCNT interlocking with the epoxy segment network. This intertwined movement of MWCNTs changed the distances between MWCNTs and the conducting paths resulting in a change in electrical conductivity, electronic impedance, and

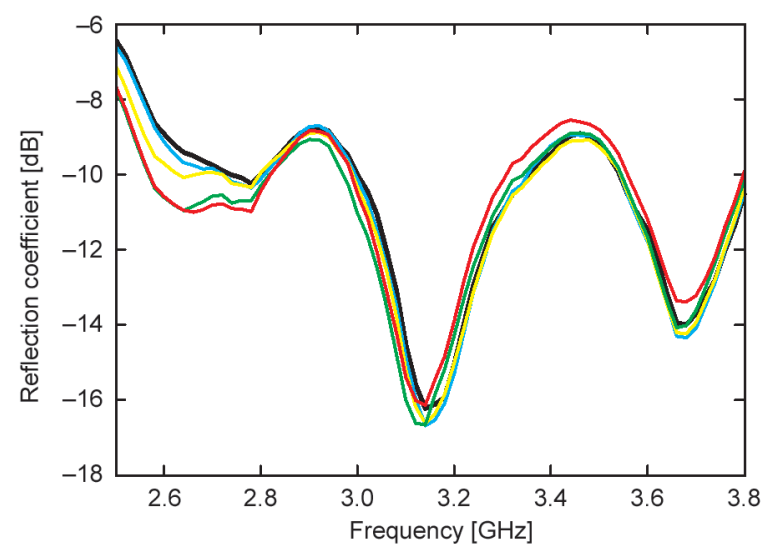

Figure 13. The reflection coefficient spectrum of the MWCNT-epoxy microstrip resonant sensor at room temperature $25^{\circ} \mathrm{C}(-)$ and at temperatures of $60^{\circ} \mathrm{C}(-), 100^{\circ} \mathrm{C}(-), 160^{\circ} \mathrm{C}$ (green line)(-), and $200^{\circ} \mathrm{C}$ (—). The composite glass transition temperature $T_{\mathrm{g}}=109^{\circ} \mathrm{C}$.

consequently, the RC spectrum of the MWCNT-epoxy microstrip sensor.

The effect of temperature on the distribution of the $\mathrm{RC}$ spectrum is shown in Figure 13. The selected temperature range of 25 to $200^{\circ} \mathrm{C}$ allows monitoring the response of the composite microstrip resonant sensor to the temperature below and above the composite $T_{\mathrm{g}}$ temperature. Owing to the possible thermal deformation of the microstrip at higher temperatures, the microstrip was glued with double-side adhesive tape to a dielectric wooden triangular support $(40 \times 8$ and base of $35 \mathrm{~mm}$ ). The added support did not change the character of the reflection coefficient spectrum but shifted it to lower both the resonant frequencies and the reflection coefficient, as can be seen in Figure 13. In the initial state before the temperature rises, there were three decreases in the RC spectrum, which were significant in determining the effect of temperature on the RC distribution. Unlike the effect of VOCs, the effect of temperature on the RC spectrum at resonant frequencies 3.15 and $3.7 \mathrm{GHz}$ did not differ significantly. On the other hand, the RC values for temperatures below and above $T_{\mathrm{g}}$ are clearly differentiated around frequency $2.7 \mathrm{GHz}$.

\section{Discussion}

This study introduced an epoxy composite consisting of an epoxy matrix and embedded conductive pristine MWCNTs and MWCNTs treated by inductively coupled ammonia plasma. The influence of the treatment method and loading of MWCNT on the cure degree, the glass transition temperature $T_{\mathrm{g}}$ and the 
elastic modulus of these epoxy composites was examined using Fourier transform infrared spectroscopy, X-ray photoelectron spectroscopy, scanning electron microscopy, differential scanning calorimeter, and creep measurement. The plasma treatment improved interfacial adhesion between MWCNTs and DGEBA but could not provide homogenous dispersion of MWCNTs within epoxy composites. As a result of this, the clusters of MWCNTs in the composites and then the decrease in C.D. values were seen. In all composites, the increase in $E$ values and the decrease in $T_{\mathrm{g}}$ values were seen together with the decrease in C.D. values. The epoxy composites with MWCNT sample $(0.4 \%)$ prepared at $40 \mathrm{~Pa}$ showed the highest elastic modulus with the lowest $T_{\mathrm{g}}$ value. The ammonia plasma treatment at $40 \mathrm{~Pa}$ caused amine and more oxygenated groups (quinone, amide, etc.) on the surface of MWCNTs compared with $300 \mathrm{~Pa}$. This facilitated the interaction of these MWCNTs with the epoxy ring, which restricted the slippage of epoxy from the surface of MWNCTs by changing stoichiometric ratio among DGEBA, HMPA, and TEA. The interactions among MWCNTs and epoxy matrix at the regions of the clusters in the composites increased elastic modulus by providing higher apparent filler loading and trapping polymer in the void space between MWCNTs.

Possible use of the MWCNT(plasma300)-Epoxy0.4\% composite was shown as a microstrip in a resonant microstrip sensor. The microstrip resonant sensor converted chemical signals elicited by the presence of chemical vapors to different spectra of the sensor reflection coefficient. Due to distinct underlying mechanisms of microstrip impedance variations, there were differences in distributions of frequency spectra of reflection coefficients. Thus reflection coefficient spectrum and the magnitude of the reflection coefficient at resonant frequencies were specific for the particular vapor. If the sensor is properly calibrated, the reflection coefficient spectrum is assignable to a specific vapor in a short amount of time, about $15 \mathrm{~s}$ after the vapor occurrence.

The composite microstrip resonant sensor also enables monitoring of the sensor response to the temperature below and above the composite $T_{\mathrm{g}}$ temperature. Accompanying the change in the microstrip impedance after temperature rise was a consequence of the polymer matrix volume increase due to its corresponding thermal expansion.
The composite microstrip sensors can provide sensing and eventually transmission of vapor monitoring since they do not need a local power source and thus could be interrogated wirelessly. The sensor integration into the matching network of the antenna and the resonant sensor could be used for remote detection of VOCs or monitoring the temperatures to which various MWCNT-epoxy composite structures are exposed.

\section{Conclusions}

The relations among cure degree, $T_{\mathrm{g}}$, and elastic modulus of epoxy composites involving modified multiwall carbon nanotubes (MWCNTs) by an ammonia ICP plasma were examined. Both the presence of MWCNTs and the increase in loading of MWCNT caused the decrease in the cure degree of all epoxy composites. The main reasons for the decrease in the cure degree values could be nanotube dispersion (i) which depends on the interaction forces between MWCNTs and the components of the mixture before curing, and the number of carbon nanotubes in the mixture and (ii) can be changed by plasma modification of carbon nanotubes. With the decrease of their cure degree, the values of elastic modulus of plasma-treated MWCNT filled epoxy composites increased, and their $T_{\mathrm{g}}$ values decreased.

This study demonstrates that the cure degree has to be considered when comparing mechanical and thermal properties, such as elastic modulus and glass transition of epoxy composites with MWCNTs treated by different plasma methods in the same loading of MWCNT. In addition, it is necessary to carry out similar studies to clarify the above-mentioned relations using various MWCNT-poxy composite systems and different preparation methods.

A microstrip resonant sensor with an MWCNT(plasma300)-Epoxy composite microstrip for the detection of volatile organic compounds and temperature has been introduced in this paper, and representative data of its ability to identify the occurrence of a particular organic vapor or changing temperature have been shown. In particular, we assessed specific differences between sensor responses in terms of spectra of the reflection coefficient for vapors of different polarity indexes. The corresponding reflection coefficient spectra made it possible to identify even a particular vapor with a precalibrated resonant sensor. 


\section{Acknowledgements}

This research was funded by the Ministry of Education, Youth and Sports of the Czech Republic-DKRVO (RP/CPS/ 2020/006); the National Budget of the Czech Republic: the project CPSV-Strengthening Research Capacity (reg. number: CZ.1.05/2.1.00/19.0409), by the Institutional support RVO: 67985874 of the Czech Academy of Sciences, Czech Republic and by the funding from Slovenian Research Agency (ARRS), grant project L2-6769 and program P2-0082.

\section{References}

[1] Thostenson E. T., Ren Z., Chou T-W.: Advances in the science and technology of carbon nanotubes and their composites: A review. Composites Science and Technology, 61, 1899-1912 (2001).

https://doi.org/10.1016/S0266-3538(01)00094-X

[2] Mittal G., Dhand V., Rhee K. Y., Park S-J., Lee W. R.: A review on carbon nanotubes and graphene as fillers in reinforced polymer nanocomposites. Journal of Industrial and Engineering Chemistry, 21, 11-25 (2015). https://doi.org/10.1016/j.jiec.2014.03.022

[3] Guo P., Chen X., Gao X., Song H., Shen H.: Fabrication and mechanical properties of well-dispersed multiwalled carbon nanotubes/epoxy composites. Composites Science and Technology, 67, 3331-3337 (2007). https://doi.org/10.1016/j.compscitech.2007.03.026

[4] Chen J., Han J.: Effect of hydroxylated carbon nanotubes on the thermal and electrical properties of derived epoxy composite materials. Results in Physics, 18, 103246 (2020). https://doi.org/10.1016/j.rinp.2020.103246

[5] Lee J., Efremov A., Son R., Pack S. P., Lee H. W., Kim K., Kwon K-H.: Ammonia-based plasma treatment of single-walled carbon nanotube thin films for bio-immobilization. Carbon, 105, 430-437 (2016).

https://doi.org/10.1016/j.carbon.2016.04.061

[6] Nejad S. M., Srivastava R., Bellussi F. M., Thielemann H. C., Asinari P., Fasano M.: Nanoscale thermal properties of carbon nanotubes/epoxy composites by atomistic simulations. International Journal of Thermal Sciences, 159, 106588 (2021).

https://doi.org/10.1016/j.ijthermalsci.2020.106588

[7] Jin F-L., Ma C-J., Park S-J.: Thermal and mechanical interfacial properties of epoxy composites based on functionalized carbon nanotubes. Materials Science and Engineering: A, 528, 8517-8522 (2011). https://doi.org/10.1016/j.msea.2011.08.054

[8] Zhang Q., Bai G., Xiao W., Sui G., Yang X.: Effect of amine functionalized MWCNT-epoxy interfacial interaction on MWCNT dispersion and mechanical properties of epoxy-amine composites. Polymer Composites, 39, 2552-2561 (2018).

https://doi.org/10.1002/pc.24832
[9] Wang S., Liang Z., Liu T., Wang B., Zhang C.: Effective amino-functionalization of carbon nanotubes for reinforcing epoxy polymer composites. Nanotechnology, 17, 1551-1557 (2006). https://doi.org/10.1088/0957-4484/17/6/003

[10] Kim J. A., Seong D. G., Kang T. J., Youn J. R.: Effects of surface modification on rheological and mechanical properties of CNT/epoxy composites. Carbon, 44, 1898-1905 (2006).

https://doi.org/10.1016/J.CARBON.2006.02.026

[11] Špitalský Z., Krontiras C. A., Georga S. N., Galiotis C.: Effect of oxidation treatment of multiwalled carbon nanotubes on the mechanical and electrical properties of their epoxy composites. Composites Part A: Applied Science and Manufacturing, 40, 778-783 (2009). https://doi.org/10.1016/j.compositesa.2009.03.008

[12] Montazeri A., Javadpour J., Khavandi A., Tcharkhtchi A., Mohajeri A.: Mechanical properties of multi-walled carbon nanotube/epoxy composites. Materials and Design, 31, 4202-4208 (2010).

https://doi.org/10.1016/j.matdes.2010.04.018

[13] Gojny F. H., Schulte K.: Functionalisation effect on the thermo-mechanical behaviour of multi-wall carbon nanotube/epoxy-composites. Composites Science and Technology, 64, 2303-2308 (2004).

https://doi.org/10.1016/j.compscitech.2004.01.024

[14] Steffen T. T., Fontana L. C., Nahorny J., Becker D.: Role of nitrogen-oxygen plasma functionalization of carbon nanotubes in epoxy nanocomposites. Polymer Composites, 40, E1162-E1171 (2019).

https://doi.org/10.1002/pc.24921

[15] Williams J., Broughton W., Koukoulas T., Rahatekar S. S.: Plasma treatment as a method for functionalising and improving dispersion of carbon nanotubes in epoxy resins. Journal of Materials Science, 48, 1005-1013 (2013).

https://doi.org/10.1007/s10853-012-6830-3

[16] Chen Z., Dai X. J., Magniez K., Lamb P. R., de Celis Leal D. R. C., Fox B. L., Wang X.: Improving the mechanical properties of epoxy using multiwalled carbon nanotubes functionalized by a novel plasma treatment. Composites Part A: Applied Science and Manufacturing, 45, 145-152 (2013).

https://doi.org/10.1016/j.compositesa.2012.09.005

[17] Liu X., Liu W., Xia Q., Feng J., Qiu Y., Xu F.: Highly tough and strain sensitive plasma functionalized carbon nanotube/epoxy composites. Composites Part A: Applied Science and Manufacturing, 121, 123-129 (2019). https://doi.org/10.1016/j.compositesa.2019.03.015

[18] Malik R., McConnell C., Alvarez N. T., Haase M., Gbordzoe S., Shanov V.: Rapid, in situ plasma functionalization of carbon nanotubes for improved CNT/epoxy composites. RSC Advances, 6, 108840-108850 (2016). https://doi.org/10.1039/C6RA23103A 
[19] Liu X., Xu F., Zhang K., Wei B., Gao Z., Qiu Y.: Characterization of enhanced interfacial bonding between epoxy and plasma functionalized carbon nanotube films. Composites Science and Technology, 145, 114-121 (2017).

https://doi.org/10.1016/j.compscitech.2017.04.004

[20] Wang S. Y., Zhang P. Z., Zhang N., Wei D. B., Wei X. $X .:$ An image-driven finite element modeling method for evaluating the stress and strain distribution in carbon nanotubes/epoxy composites. Materials Research Express, 6, 125611 (2019).

https://doi.org/10.1088/2053-1591/ab54b5

[21] Jung H., Choi H. K., Oh Y., Hong H., Yu J.: Enhancement of thermo-mechanical stability for nanocomposites containing plasma treated carbon nanotubes with an experimental study and molecular dynamics simulations. Scientific Reports, 10, 405 (2020). https://doi.org/10.1038/s41598-019-56976-w

[22] Allaoui A., El Bounia N. E.: How carbon nanotubes affect the cure kinetics and glass transition temperature of their epoxy composites? - A review. Express Polymer Letters, 3, 588-594 (2009).

https://doi.org/10.3144/expresspolymlett.2009.73

[23] Chen W-Y., Wang Y-Z., Kuo S-W., Huang C-F., Tung P-H., Chang F-C.: Thermal and dielectric properties and curing kinetics of nanomaterials formed from possepoxy and meta-phenylenediamine. Polymer, 45, 68976908 (2004).

https://doi.org/10.1016/j.polymer.2004.07.070

[24] Yang K., Gu M., Jin Y.: Cure behavior and thermal stability analysis of multiwalled carbon nanotube/epoxy resin nanocomposites. Journal of Applied Polymer Science, 110, 2980-2988 (2008).

https://doi.org/10.1002/app.28898

[25] Ozaytekin I., Turedi H. E., Ahmetli G.: Preparation of epoxy composites with CTAB-modified BN and MWCNTs. Polymer Composites, 37, 3423-3432 (2015). https://doi.org/10.1002/pc.23542

[26] Abdalla M., Dean D., Robinson P., Nyairo E.: Cure behavior of epoxy/MWCNT nanocomposites: The effect of nanotube surface modification. Polymer, 49, 33103317 (2008).

https://doi.org/10.1016/j.polymer.2008.05.016

[27] Estrade-Szwarckopf H.: XPS photoemission in carbonaceous materials: A 'defect' peak beside the graphitic asymmetric peak. Carbon, 42, 1713-1721 (2004). https://doi.org/10.1016/j.carbon.2004.03.005

[28] Felten A., Bittencourt C., Pireaux J. J., van Lier G., Charlier J. C.: Radio-frequency plasma functionalization of carbon nanotubes surface $\mathrm{O}_{2}, \mathrm{NH}_{3}$, and $\mathrm{CF}_{4}$ treatments. Journal of Applied Physics, 98, 074308 (2005). https://doi.org/10.1063/1.2071455

[29] Kim M. J., Jeong Y., Sohn S., Lee S. Y., Kim Y. J., Lee K., Khang Y. H., Jang J-H.: Fast and low-temperature reduction of graphene oxide films using ammonia plasma. AIP Advances, 3, 012117 (2013).

https://doi.org/10.1063/1.4789545
[30] Hafiz S. M., Ritikos R., Whitcher T. J., Razib N. M., Bien D. C. S., Chanlek N., Nakajima H., Saisopa T., Songsiriritthigul P., Huang N. M., Rahman S. A.: A practical carbon dioxide gas sensor using room-temperature hydrogen plasma reduced graphene oxide. Sensors and Actuators B: Chemical, 193, 692-700 (2014). https://doi.org/10.1016/j.snb.2013.12.017

[31] Shen J., Huang W., Wu L., Hu Y., Ye M.: Thermo-physical properties of epoxy nanocomposites reinforced with amino-functionalized multi-walled carbon nanotubes. Composites Part A: Applied Science and Manufacturing, 38, 1331-1336 (2007).

https://doi.org/10.1016/j.compositesa.2006.10.012

[32] Puliyalil H., Slobodian P., Sedlacik M., Benlikaya R., Riha P., Ostrikov K., Cvelbar U.: Plasma-enabled sensing of urea and related amides on polyaniline. Frontiers of Chemical Science and Engineering, 10, 265-272 (2016). https://doi.org/10.1007/s11705-016-1570-6

[33] Zhang X., Lei L., Xia B., Zhang Y., Fu J.: Oxidization of carbon nanotubes through hydroxyl radical induced by pulsed $\mathrm{O}_{2}$ plasma and its application for $\mathrm{O}_{2}$ reduction in electro-Fenton. Electrochimica Acta, 54, 28102817 (2009).

https://doi.org/10.1016/j.electacta.2008.11.029

[34] Taylor J. A., Lancaster G. M., Rabalais J. W.: Interactions of nitrogen $\left(\mathrm{N}_{2}^{+}\right)$and nitrosyl $\left(\mathrm{NO}^{+}\right)$ions with surfaces of graphite, diamond, teflon, and graphite monofluoride. Journal of the American Chemical Society, 100, 4441-4447 (1978). https://doi.org/10.1021/ja00482a021

[35] Yook J. Y., Jun J., Kwak S.: Amino functionalization of carbon nanotube surfaces with $\mathrm{NH}_{3}$ plasma treatment. Applied Surface Science, 256, 6941-6944 (2010). https://doi.org/10.1016/j.apsusc.2010.04.075

[36] Hueso J. L., Espinós J. P., Caballero A., Cotrino J., González-Elipe A. R.: XPS investigation of the reaction of carbon with $\mathrm{NO}, \mathrm{O}_{2}, \mathrm{~N}_{2}$ and $\mathrm{H}_{2} \mathrm{O}$ plasmas. Carbon, 45, 89-96 (2007). https://doi.org/10.1016/j.carbon.2006.07.021

[37] Kameoka S., Kuriyama T., Kuroda M., Ito S., Kunimori K.: The chemical interaction between plasma-excited nitrogen and the surface of titanium dioxide. Applied Surface Science, 89, 411-415 (1995). https://doi.org/10.1016/0169-4332(95)00052-6

[38] Benlikaya R., Slobodian P., Riha P., Olejnik R.: The enhanced alcohol sensing response of multiwalled carbon nanotube networks induced by alkyl diamine treatment. Sensors and Actuators B: Chemical, 201, 122-130 (2014).

https://doi.org/10.1016/j.snb.2014.04.057

[39] Slobodian P., Riha P., Olejnik R., Benlikaya R.: Analysis of sensing properties of thermoelectric vapor sensor made of carbon nanotubes/ethylene-octene copolymer composites. Carbon, 10, 257-266 (2016). https://doi.org/10.1016/j.carbon.2016.09.023 
[40] Saito T., Matsushige K., Tanaka K.: Chemical treatment and modification of multi-walled carbon nanotubes. Physica B, 323, 280-283 (2002). https://doi.org/10.1016/S0921-4526(02)00999-7

[41] Zhang G., Qi P., Wang X., Lu Y., Mann D., Li X., Dai H.: Hydrogenation and hydrocarbonation and etching of single-walled carbon nanotubes. Journal of the American Chemical Society, 128, 6026-6027 (2006). https://doi.org/10.1021/ja061324b

[42] Stobinski L., Lesiak B., Kövér L., Tóth J., Biniak S., Trykowski G., Judek J.: Multiwall carbon nanotubes purification and oxidation by nitric acid studied by the FTIR and electron spectroscopy methods. Journal of Alloys and Compounds, 501, 77-84 (2010). https://doi.org/10.1016/j.jallcom.2010.04.032

[43] Benlikaya R., Slobodian P., Riha P.: Enhanced straindependent electrical resistance of polyurethane composites with embedded oxidized multiwalled carbon nanotube networks. Journal of Nanomaterials, 2013, 327597 (2013).

https://doi.org/10.1155/2013/327597

[44] Shahverdi A., Soucy G., Simard B., Mostaghimi J.: Effect of ammonia gas addition to the synthesis environment of single-walled carbon nanotubes on their surface chemistry. Chemical Engineering Journal, 230, 80-92 (2013).

https://doi.org/10.1016/j.cej.2013.06.062

[45] Scheibe B., Borowiak-Palen E., Kalenczuk R. J.: Oxidation and reduction of multiwalled carbon nanotubes - Preparation and characterization. Materials Characterization, 61, 185-191 (2010).

https://doi.org/10.1016/j.matchar.2009.11.008

[46] Delor-Jestin F., Drouin D., Cheval P-Y., Lacoste J.: Thermal and photochemical ageing of epoxy resin - Influence of curing agents. Polymer Degradation and Stability, 91, 1247-1255 (2006).

https://doi.org/10.1016/j.polymdegradstab.2005.09.009

[47] Jain R., Kukreja P., Narula A. K., Chaudhary V.: Studies of the curing kinetics and thermal stability of epoxy resins using a mixture of amines and anhydrides. Journal of Applied Polymer Science, 100, 3919-3925 (2006). https://doi.org/10.1002/app.22769

[48] de Simone Cividanes L., Simonetti E. A. N., de Oliveira J. I. S., Serra A. A., de Souza Barboza J. C., Thim G. P.: The sonication effect on CNT-epoxy composites finally clarified. Polymer Composites, 38, 1965-1973 (2017). https://doi.org/10.1002/pc.23767

[49] Tanabi H., Erdal M.: Effect of CNTs dispersion on electrical, mechanical and strain sensing properties of CNT/ epoxy nanocomposites. Results in Physics 12, 486-503 (2019).

https://doi.org/10.1016/j.rinp.2018.11.081
[50] Tang L-C., Zhang H., Han J-H., Wu X-P., Zhang Z. Fracture mechanisms of epoxy filled with ozone functionalized multi-wall carbon nanotubes. Composites Science and Technology, 72, 7-13 (2011).

https://doi.org/10.1016/j.compscitech.2011.07.016

[51] Hirsch A.: Functionalization of single-walled carbon nanotubes. Angewandte Chemie International Edition, 41, 1853-1859 (2002).

https://doi.org/10.1002/1521-

3773(20020603)41:11<1853::AID-ANIE1853>3.0.CO;2-N

[52] Puglia D., Valentini L., Armentano I., Kenny J. M.: Effects of single-walled carbon nanotube incorporation on the cure reaction of epoxy resin and its detection by Raman spectroscopy. Diamond and Related Materials, 12, 827-832 (2003).

https://doi.org/10.1016/S0925-9635(02)00358-8

[53] Tao K., Yang S., Grunlan J. C., Kim Y-S., Dang B., Deng Y., Thomas R. L., Wilson B. L., Wei X.: Effects of carbon nanotube fillers on the curing processes of epoxy resin-based composites. Journal of Applied Polymer Science, 102, 5248-5254 (2006).

https://doi.org/10.1002/app.24773

[54] Siegfried M., Tola C., Claes M., Lomov S. V., Verpoest I., Gorbatikh L.: Impact and residual after impact properties of carbon fiber/epoxy composites modified with carbon nanotubes. Composite Structures, 111, 488-496 (2014).

https://doi.org/10.1016/j.compstruct.2014.01.035

[55] Aravand M., Lomov S. V., Verpoest I., Gorbatikh L.: Evolution of carbon nanotube dispersion in preparation of epoxy-based composites: From a masterbatch to a nanocomposite. Express Polymer Letters, 8, 596-608 (2014).

https://doi.org/10.3144/expresspolymlett.2014.63

[56] González-Domínguez J. M., Ansón-Casaos A., DiezPascual A. M., Ashrafi B., Naffakh M., Backman D., Stadler H., Johnston A., Gómez M., Martínez M. T.: Solvent-free preparation of high-toughness epoxySWNT composite materials. ACS Applied Materials and Interfaces, 3, 1441-1450 (2011).

https://doi.org/10.1021/am101260a

[57] Zhou T., Wang X., Liu X., Xiong D.: Influence of multiwalled carbon nanotubes on the cure behavior of epoxyimidazole system. Carbon, 47, 1112-1118 (2009). https://doi.org/10.1016/j.carbon.2008.12.039

[58] Slobodian P., Riha P., Olejnik R., Matyas J., Slobodian R.: Microstrip resonant sensor for differentiation of components in vapor mixtures. Sensors, 21, 298 (2021). https://doi.org/10.3390/s21010298 